\title{
Projection of Korean Probable Maximum Precipitation under Future Climate Change Scenarios
}

\author{
Okjeong Lee, ${ }^{1}$ Yoonkyung Park, ${ }^{1}$ Eung Seok Kim, ${ }^{2}$ and Sangdan Kim ${ }^{3}$ \\ ${ }^{1}$ Division of Earth Environmental System Science (Major of Environmental Engineering), Pukyong National University, Busan 48513, \\ Republic of Korea \\ ${ }^{2}$ Department of Civil Engineering, Sunmoon University, Chunman 31460, Republic of Korea \\ ${ }^{3}$ Department of Environmental Engineering, Pukyong National University, Busan 48513, Republic of Korea
}

Correspondence should be addressed to Sangdan Kim; skim@pknu.ac.kr

Received 5 May 2016; Revised 12 August 2016; Accepted 19 September 2016

Academic Editor: Stefano Dietrich

Copyright (C) 2016 Okjeong Lee et al. This is an open access article distributed under the Creative Commons Attribution License, which permits unrestricted use, distribution, and reproduction in any medium, provided the original work is properly cited.

\begin{abstract}
According to the IPCC Fifth Assessment Report, air temperature and humidity of the future are expected to gradually increase over the current. In this study, future PMPs are estimated by using future dew point temperature projection data which are obtained from RCM data provided by the Korea Meteorological Administration. First, bias included in future dew point temperature projection data which is provided on a daily basis is corrected through a quantile-mapping method. Next, using a scale-invariance technique, 12-hour duration 100-year return period dew point temperatures which are essential input data for PMPs estimation are estimated from bias-corrected future dew point temperature data. After estimating future PMPs, it can be shown that PMPs in all future climate change scenarios (AR5 RCP2.6, RCP 4.5, RCP 6.0, and RCP 8.5) are very likely to increase.
\end{abstract}

\section{Introduction}

Huge disasters occurring more and more frequently have been one of very important issues in the world. Floods caused by torrential rains including super typhoons are giving loss of lives and causing enormous economic losses. Losses due to storm and flood damage are increasing every year and the occurrence of huge disasters caused by abnormal climate conditions reminds us of the need for a fundamental shift in the perception of each country's disaster prevention system. Frequent emergence of big disaster events means that the impact of climate change should be considered in the estimation procedure for the probable maximum precipitation (PMP) which should be applied to the design and evaluation of large hydraulic structures since the destruction of such large-scale hydraulic structures may cause a large loss of life and enormous economic losses.

According to the WMO (World Meteorological Organization) [1], PMPs are defined as the maximum precipitation that may occur physically in a specific time period on a specific area. Since Paulhus and Gilman [2] conducted a study on the PMP estimation considering the physical state of the atmosphere, many studies have been performed. Myers [3] reviewed the historical reasons to apply the PMP approach to design the spillways of most large dams built in the United States and summarized the estimation procedures. After that, the US National Weather Service has been applied to a hydrometeorological method to improve the estimation method of PMP [4].

WMO has published a number of reports describing standardized methods and procedures of the PMPs estimation from 1969 until recently. WMO [1] is divided into two methods for estimating PMPs: (1) hydrometeorological method to maximize rainfall events based on moisture maximizing processes and (2) statistical method to estimate PMPs in the case that various meteorological data are scarce. PMPs estimates based on hydrometeorological methods are most widely applied in the world. Detailed procedures applying to hydrometeorological methods are slightly different depending on the amount of available data or location of the basin 
TABLE 1: Scale and resolution of climate change scenarios.

\begin{tabular}{|c|c|c|c|c|c|c|c|}
\hline Class & Variable & Form & Scenario & Spatial scale & $\begin{array}{c}\text { Spatial } \\
\text { resolution }\end{array}$ & $\begin{array}{l}\text { Temporal } \\
\text { resolution }\end{array}$ & Temporal scale \\
\hline \multirow{2}{*}{ Korea Peninsula } & $\begin{array}{c}\text { Average } \\
\text { temperature }\end{array}$ & \multirow{2}{*}{ BINARY } & \multirow{2}{*}{$\begin{array}{c}\text { RCP } \\
2.6 / 4.5 / 6.0 / 8.5\end{array}$} & Longitude $123^{\circ} \sim 133^{\circ}$ & \multirow{2}{*}{$12.5 \mathrm{~km}$} & \multirow{2}{*}{$\begin{array}{c}\text { Day } \\
\text { (360-day) }\end{array}$} & Present 1981 2005 \\
\hline & $\begin{array}{c}\text { Representative } \\
\text { humidity }\end{array}$ & & & Latitude $\quad 32^{\circ} \sim 44^{\circ}$ & & & Future $\quad 2006 \sim 2100$ \\
\hline
\end{tabular}

[5], and it is clear that the process that maximizes moisture conditions is the core in estimating PMPs.

When estimating PMPs using hydrometeorological methods, the most common way to consider the impact of climate change is to use regional climate models (RCMs). In other words, the future climate information derived from RCMs is regarded as future new observations, and future PMPs are estimated using them. Kunkel et al. [6] analyzed global maximum precipitable water changes using several GCM results and estimated indirectly the change of PMPs through them. Using the atmospheric model RAMS (Regional Atmospheric Modeling System), Stratz and Hossain [7] reported that changes in land-cover condition cause a change in the hydrologic cycle, which results in a change of PMPs. Lagos-Zúñiga and Vargas $M$ [8] also estimated futures PMPs by statistical methods and hydrometeorology methods using the future climate information derived from GCMs, and Rousseau et al. [9] also estimated future PMPs in accordance with the change of the maximum precipitable water calculated from the future climate information derived from RCMs. In general, it can be thought that future PMPs are estimated to reflect the changes in precipitable water (in practice, changes in the dew point temperature) rather than to reflect the changes in precipitation. This is because the uncertainty of the future temperature projection is much smaller than the uncertainty of future precipitation projection. For example, Lee et al. [10] estimated future Korean PMPs reflecting future precipitation scenarios derived from the Korea Meteorological Administration RCM. In their study, PMPs at the relatively distant future were estimated to have unrealistically large values. They concluded that these abnormal PMPs estimates were due to the big uncertainty of future precipitation projections.

Thus, this study pays attention to the change in the dew point temperature in order to investigate the extent of the change in PMPs taking into account climate change. In addition, since future dew point data provided by the Korea Meteorological Administration (KMA) RCM are given on a daily basis, 12-hour duration 100-year dew point temperatures are calculated by using a scaling-invariance technique to estimate future PMPs. This paper is organized as follows. The data used is described in Section 2. The PMPs are estimated using historical data in Section 3, and several methods to obtain the future climate information for estimating PMPs are described in Section 4. In Section 5, PMPs estimated at a certain future period are analyzed. Finally, Section 6 is a summary and conclusions.

\section{Data}

2.1. Observation Data. In this study, the data of 62 weather stations that have been operated for more than 40 years by Korea Meteorological Administration are used, and the spatial extent of the data is shown in Figure 1.

Meteorological data observed from 1981 to 2005 (the same as the control period of KMA RCM) are used. Hourly precipitation data and 3-hour-interval dew point temperature data are mainly used. Spatial resolution in the estimation of PMPs is $5 \mathrm{~km} \times 5 \mathrm{~km}$. Observation data for each site are extend into the gridded data $(5 \mathrm{~km} \times 5 \mathrm{~km})$ using inverse distance weighting method.

\subsection{Future Climate Information Driven by KMA RCM under} AR5 RCP Climate Change Scenarios. Future climate change scenarios in the IPCC 5th assessment report [11] are classified into RCP 2.6, RCP 4.5, RCP 6.0, and RCP8.5 depending on the level of climate change adaptation policy. Accordingly, KMA has provided future climate information on four AR5 climate change scenarios through the climate information portal (https://www.climate.go.kr/). Provided data are classified into three categories:

(1) Global data with $135 \mathrm{~km}$ spatial resolution produced by UK Hadley Centre climate change prediction model HadGEM2-AO

(2) Korean Peninsula data with $12.5 \mathrm{~km}$ spatial resolution produced by UK Hadley Centre regional climate model HadGEM3-RA

(3) South Korea detailed data with $1 \mathrm{~km}$ spatial resolution produced by KMA statistical downscaling method

In this study, Korean Peninsula data with $12.5-\mathrm{km}$ spatial resolution are used since the data can provide the most appropriate future climate information on estimating future PMPs. Details of the data can be seen in Table 1.

\section{PMPs Estimation Using Historical Data}

3.1. Basic Concept. PMPs estimation by a hydrometeorological method is based on the method, which is recommended in WMO [12]. The core of PMPs estimation is to maximize observed extreme precipitation amount by using the relationship between the observed representative precipitable water and the theoretically maximum precipitable water, and to transpose the maximized extreme precipitation amount into other regions. The procedure of estimating PMPs is 


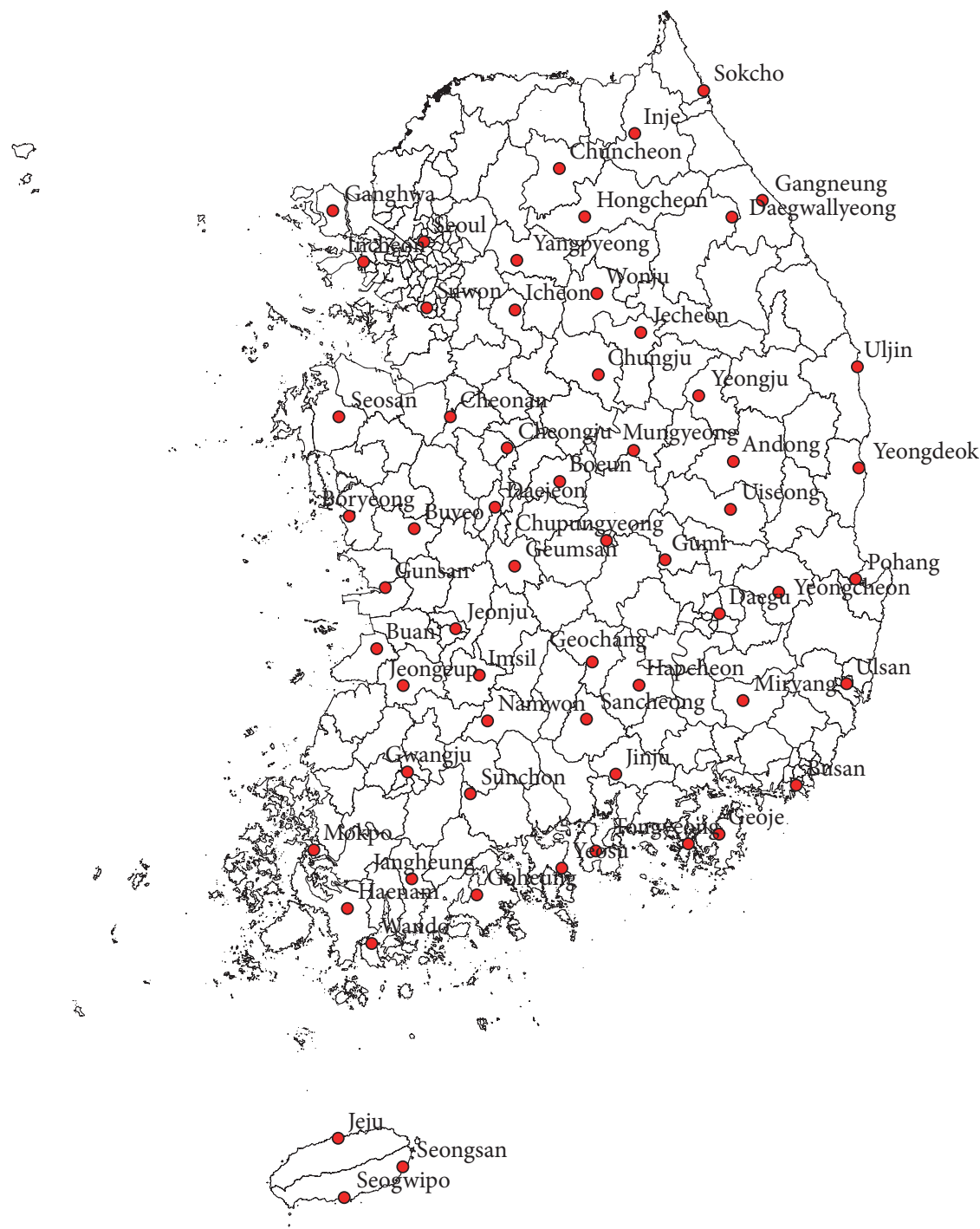

8 . Ulleungdo

FIGURE 1: Location of selected weather stations.

largely divided into 5 steps: identification of high-efficiency precipitation events, moisture maximization, transposition, enveloping, and PMPs calculation for each duration and for each effective area from enveloped Depth-Area-Duration (DAD) curves (see Figure 2).

The first step is to identify several major storm events as high-efficiency storms with the assumption that their precipitation efficiency has reached the maximum. Moisture maximization is the process adjusting moisture factors of high-efficiency storms to their maximum. The transposition is the process transposing the maximized precipitation into the area of interest. When transposing, the maximized precipitation is adjusted since meteorological characteristics of the area of interest should be taken into account. Enveloping means that enveloping values are taken from the DAD relation plotted according to the transposed storms, thereby maximizing the precipitation depth for various areas and durations. PMPs are the possible maximum precipitations that come from the application of the above DAD enveloping values for a region of interest.

3.2. Basic Equations. Actual PMP estimation procedure is simplified to maximize moisture, to transport storms, and to envelope. Precipitation adjusted by moisture maximization and storm transposition is expressed as follows:

$$
\mathrm{AP}=R_{\mathrm{IP}} \cdot R_{\mathrm{HT}} \cdot R_{\mathrm{VT}} \cdot \mathrm{OTF} \cdot \mathrm{OP},
$$

where $\mathrm{AP}$ is the adjusted precipitation, $R_{\mathrm{IP}}$ is the moisture maximization ratio, $R_{\mathrm{HT}}$ is the horizontal transposition ratio, $R_{\mathrm{VT}}$ is the vertical transpiration ratio, OTF is the orographic transposition factor, and OP is the observed storm precipitation which is the spatially averaged precipitation and is derived from DAD relationship. That is, the observed precipitation is maximized by using the ideal maximum moisture 


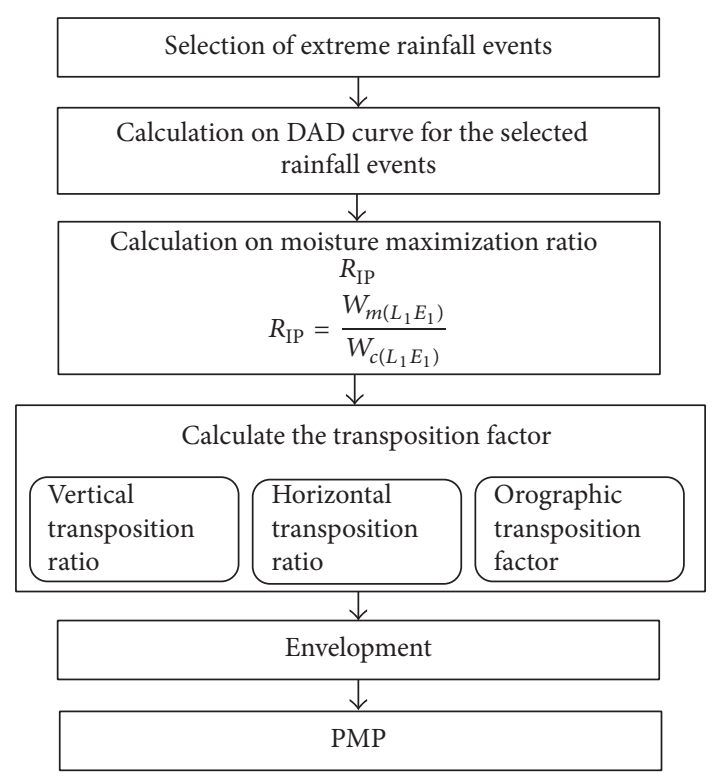

FIGURE 2: Procedure of PMPs estimation.

conditions (moisture maximization), the maximized precipitation is transposed to reflect the ideal moisture conditions of the transition area (horizontal and vertical transition), and the transposed precipitation is finally adjusted to consider the effect of the mountains (orographic transposition). After obtaining adjusted precipitations from various major storm events, PMPs can be estimated by enveloping them with respect to storm durations and affected areas.

3.3. Moisture Maximization and Storm Transposition. The efficiency of storm is closely related to the precipitable water of the atmosphere. The precipitable water is the total mass of water vapor in a vertical column of the atmosphere. However, direct measurement of precipitable water has many problems. To solve this issue, the storm efficiency is evaluated using the correlated relationship between precipitable water and surface dew point temperature. The moisture maximization ratio based on the moisture maximization efficiency concept is a major element for estimating PMPs.

Moisture maximization ratio of a storm in place, that is, without change in location, is calculated by simply multiplying the observed precipitation amount by the moisture maximization ratio $R_{\mathrm{IP}}$. It represents the formula shown below [12]:

$$
R_{\mathrm{IP}}=\frac{W_{m\left(L_{1} E_{1}\right)}}{W_{c\left(L_{1} E_{1}\right)}}
$$

where $W_{m\left(L_{1} E_{1}\right)}$ is precipitable water equivalent of the maximum persisting 12-hour 1000-hpa dew point temperature for the date of storm occurrence (plus 15 days) and $W_{c\left(L_{1} E_{1}\right)}$ is precipitable water equivalent of the representative persisting 12-hour 1000-hpa dew point temperature.

As an example of the storm event which occurred at Gangreung from August 29th 2002 to September 1st 2002, the representative persisting 12 -hour 1,000-hpa storm dew
Example storm center to grid point 24-hour proportionality constant

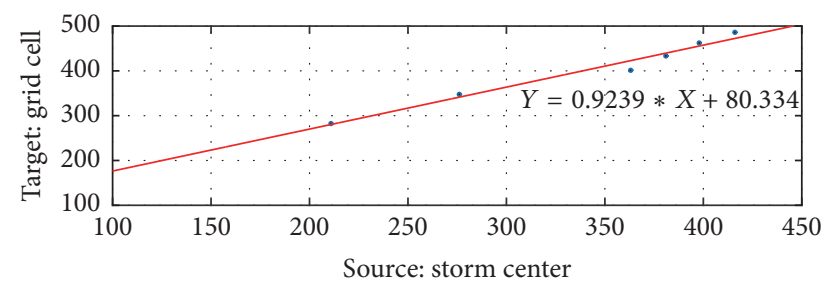

FIGURE 3: Regression estimation for OTF.

point is $21.70^{\circ} \mathrm{C}$ and the maximum is $26.16^{\circ} \mathrm{C}$. Hence, the moisture maximization ratio is computed from precipitable water values obtained from Table A.1.1 in Annex of WMO [12]: $R_{\mathrm{IP}}=88.73 / 60.14=1.48$.

Horizontal transposition ratio of a storm is the adjustment for the difference in maximum dewpoints between the original and transposed locations under no change in elevation. It is expressed as follows:

$$
R_{\mathrm{HT}}=\frac{W_{m\left(L_{2} E_{1}\right)}}{W_{m\left(L_{1} E_{1}\right)}} .
$$

Vertical transposition ratio is the elevation adjustment and is expressed as follows:

$$
R_{\mathrm{VT}}=0.5+0.5 \frac{W_{c\left(L_{1} E_{1}\right)}}{W_{m\left(L_{1} E_{1}\right)}} .
$$

Since the storm transposition process is based on the assumption of the geomorphological and meteorological homogeneity, the effects of terrain on precipitation should be considered. OTF provides quantifiable and reproducible analyses of orographic effects on PMPs as follows:

$$
\mathrm{OTF}=\frac{P_{o}}{P_{i}},
$$

where $P_{o}$ is the orographically adjusted precipitation at target location and $P_{i}$ is the historically 24 -hour maximum precipitation. The orographic relationship is defined as the linear relationship of the precipitation frequency values at 24hour duration over a range of recurrence intervals between the source and target locations $(y=0.9239 x+80.334$ in Figure 3 ). $P_{i}$ is entered as the $x$-value to compute the target $y$-value $P_{o}$.

According to Miller et al. [13, 14], the upper limitation of moisture maximization ratio is recommended as high as 1.70. However, in order to see more clearly at the value of PMPs which change according to the climate change, to get reliable maximized precipitations and not to produce exaggerated maximized precipitation values, upper boundaries are defined for the maximization ratios: a maximum value is set to 2.0. This adjustment refers to Rousseau et al. [9].

Storm transition ratio is divided into horizontal transposition ratio, vertical transposition ratio, and orographic transposition factor (OTF). Horizontal and vertical transition ratios' limits are set to 1.2 according to Miller et al. [13, 14]. The lower and upper bound of OTF are set to 0.5 and 1.5, respectively [15-17]. 


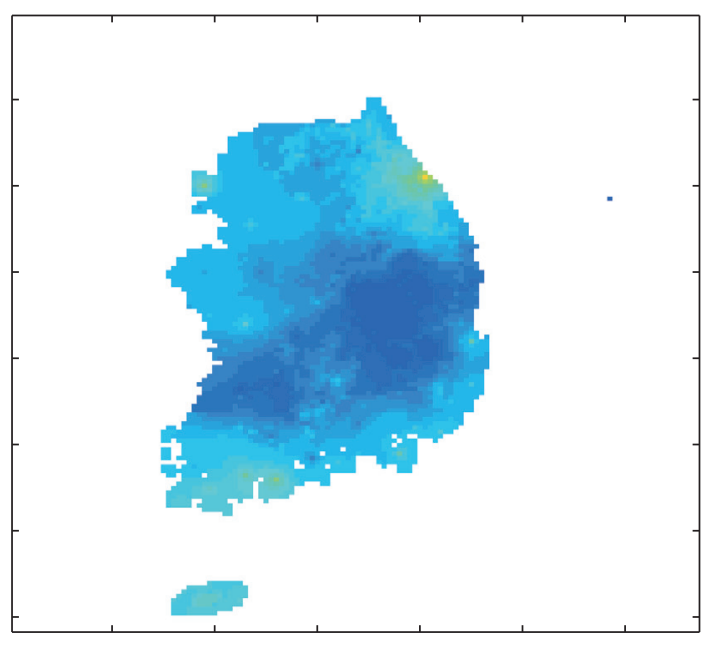

(a) $12 \mathrm{hr}-25 \mathrm{~km}^{2}$

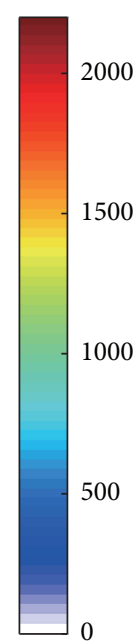

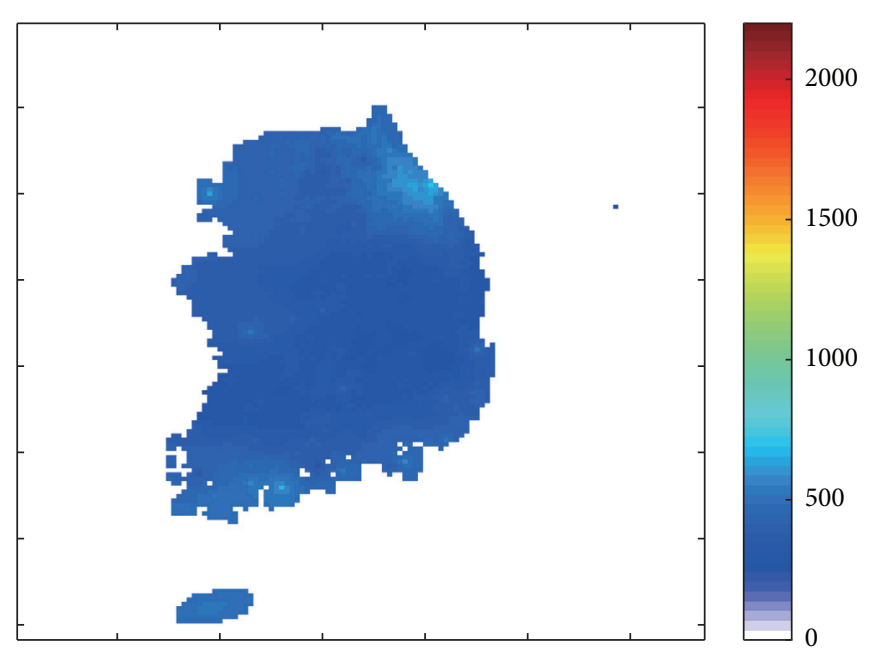

(b) $24 \mathrm{hr}-10,000 \mathrm{~km}^{2}$

FIGURE 4: PMP maps using historical data (mm).

3.4. PMPs Estimation Using Historical Data. Table 2 shows the grid-averaged mean and standard deviation of PMPs estimated using historical data (1981-2005). The values of ( ) are standard deviation values. For the duration of 24-hour and effective area $25 \mathrm{~km}^{2}$, it can be seen that the average PMP is estimated to be about $760 \mathrm{~mm}$, and its spatial standard deviation is about $101 \mathrm{~mm}$ (about 13\% of averaged value). In order to confirm the spatial variability of PMPs, PMP maps of 12-hour duration and effective area $25 \mathrm{~km}^{2}$ and 24-hour duration and effective area $10,000 \mathrm{~km}^{2}$ are shown in Figure 4.

\section{Production of Future Climate Information for Estimating Future PMPs}

4.1. Future Daily Dew Point Temperature. In order to estimate PMPs using the hydro-meteorological method, 12-hr 100year dew point temperature data are needed. However, KMA RCM currently does not provide future dew point temperatures separately. However, future daily average air temperature and relative humidity are provided. Therefore, the future dew point temperature can be calculated as follows:

$$
\begin{aligned}
t-t_{d} \cong & (14.55+0.114 t) x+[(2.5+0.007 t) x]^{3} \\
& +(15.9+0.117 t) x^{14}, \\
x= & 1-\mathrm{RH},
\end{aligned}
$$

where $t_{d}$ is the dew point temperature $\left({ }^{\circ} \mathrm{C}\right), t$ is daily average air temperature $\left({ }^{\circ} \mathrm{C}\right)$, and $\mathrm{RH}$ is the daily relative humidity (\%), respectively.

4.2. Bias Correction. Since output-data of RCMs has usually biases to a degree, it is difficult to use it directly in climate change impact studies. In order to overcome this bias problem, a bias correction procedure which is the correction of model output towards observations has become a standard procedure [18].

In this study, the bias correction for the dew point temperature is performed for each observation site and for each period of half-month from October to May, respectively. The bias correction is carried out using the Kernel density distribution mapping (KDDM) method. The KDDM estimates the cumulative probability density function (CDF) of each dataset using kernel density estimation and is implemented by quantile-mapping the CDF of a present climate variable obtained from the RCM onto that of the corresponding observed climate variable [19]. For instance, the CDF of data simulated as the first-half May dew point temperature driven by KMA RCM and that of the corresponding observed data are mapped onto each other. If the CDF of observed data $D_{o}$ is assumed to be $F_{o}\left(D_{o}\right)$ and the CDF of RCM-driven data $D_{c}$ is assumed to be $F_{c}\left(D_{c}\right)$, the bias-corrected value $D_{c}^{\prime}$ for $D_{c}$ can be obtained by $F_{o}^{-1}\left(F_{c}\left(D_{c}\right)\right)$, where $F_{o}^{-1}$ refers to the inverse function of $F_{o}$. Matlab statistic toolbox function "ksdensity" is used to compute a probability density estimate.

Prior to correcting the bias of climate data obtained from the RCM, it is necessary to verify the adequacy of the bias correction method. Currently in Korea, a variety of bias correction methods have been applied ([19, 20]; and many others); verification of the adequacy of these methods has not been attempted.

First, using historical data and the corresponding RCMdriven data for calibration period (1981-1993), a functional relationship for correcting bias by KDDM method is built. Using the established functional relationship, the bias of the RCM-driven data for verification period (1994-2005) is corrected.

The results of the bias correction of RCM-driven data for verification period show that various statistics of biascorrected RCM-driven data are very similar to historical data. Figure 5 illustrates the reproducibility of the average dew 


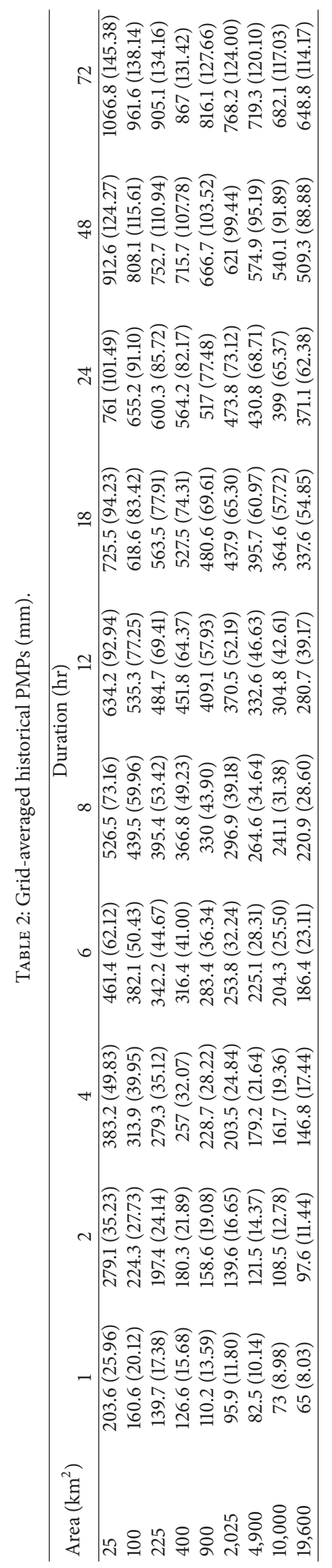




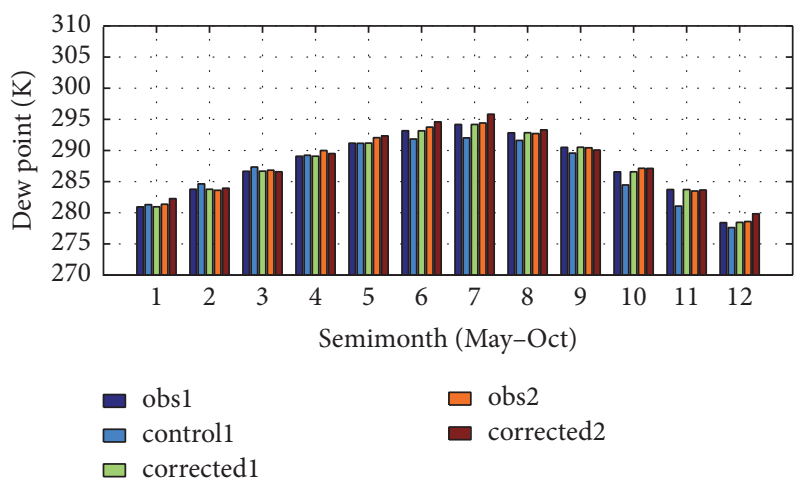

Figure 5: Bias correction result (Sokcho site).

point temperature at Sokcho site. In this figure, "obs1" and "controll" are the average of historical data and the corresponding RCM-driven data for calibration period, respectively. The "correctedl" is the average of the bias-corrected RCM-driven data for calibration period. The "obs2" and "corrected2" are the average of historical data and the corresponding bias-corrected RCM-driven data for verification period, respectively. In both calibration period and verification period, it can be confirmed that the bias-corrected RCMdriven data match the corresponding historical data overall. Hence, it is thought to be appropriate to apply the KDDM method for bias correction of dew point temperature.

Based on these results, the bias of future dew point data obtained from KMA RCM is corrected by using the KDDM method.

4.3. 12-Hour Duration 100-Year Dew Point Temperature. In order to estimate PMPs using hydrometeorological methods, 12-hour duration 100-year dew point temperature data are needed. In this study, these data are extracted from daily data using scale-invariance techniques $[21,22]$. The straightforward approach is to assume that the relative variations between the present and future dew point temperature are the same for any duration shorter than 1-day.

Prior to applying scale-invariance technique to obtain future 12-hour duration 100-year dew point temperature data, it is necessary to verify the adequacy of the applied method. Using historical data for calibration period (19811997), a scale-invariance relationship to produce 12-hour duration 100-year dew point temperature data is built. Using the established relationship, 12-hour duration 100-year dew point temperature data for verification period (1998-2014) are produced from the corresponding daily data.

Figure 6(a) shows the linear relationship found between the scaling exponent $n(r)$ and the order $r$ of the statistical moments. Therefore, one can assume wide sense simple scaling to hold for the investigated process. By adopting the properties of scale-invariance, $d$-hour duration $T$-year dew point temperature can be expressed as [21]

$$
\xi_{T}(\lambda)=E\left[D_{1 d}\right] \cdot\left(1+V \cdot K_{T}\right)(\lambda)^{n_{T}},
$$

where $\lambda=d / 24(\mathrm{hr}),\left[D_{1 d}\right]=$ the expected value of annual maximum daily dew point temperature $D_{1 d}, V=$ the overall coefficient of variation by taking the square root of the averaged squared values of the coefficient of variation computed for the different durations, $K_{T}=$ the frequency factor, and $n_{T}=$ the scaling exponent corresponding return period $T$. In (7), it is assumed that annual maximum daily dew point temperature series and annual maximum 24-hour duration dew point temperature series have established a linear relationship to each other. The values of $K_{T}$ and $n_{T}$ can be estimated by linear regression of the log-transformed expectations of dew point temperature against the corresponding logtransformed durations.

Figures 6(b) and 6(c) show that the 12-hour duration 100 -year dew point temperature data produced by the scaleinvariance technique has a good consistency with the corresponding original data. Hence, it is thought to be appropriate to apply the scale-invariance technique for producing 12hour duration 100-year dew point temperature data from the corresponding daily data.

Based on these results, scale-invariance relationships are constructed for each observation site and for each period of half-month from October to May, respectively. However, there is no choice but to be the difference between extreme dew point temperatures derived from the present climate RCM data and the corresponding observed extreme dew point temperatures (see Figure 7). Although present extremes are slightly overestimated, differences between present and observed extremes are at most approximately $20 \mathrm{~mm}$. In addition, since future PMPs are compared with present PMPs (not observed PMPs), the effect of such differences on future PMP analysis would be limited.

Future annual maximum daily dew point temperature series obtained in the bias correction procedure can be fitted to as follows:

$$
D_{t}^{f}=b t+0.5 a t^{2}
$$

where $b$ and $a$ are coefficients representing a base rate and acceleration of annual maximum daily dew point temperature series, respectively. The origin of $t$ in (8) is 2004 in this study since KMA RCM starts its future simulation from 2005. The multiplier 0.5 is introduced to consider the coefficient a as a physical acceleration term. Figure 8 shows the projected annual maximum daily dew point temperatures at a specific period with the corresponding 95\% confidence interval of trend analysis using (8).

Using the established scale-invariance relationships and the quadratic trend (8) for future annual maximum daily dew point temperature series, future 12-hour duration 100year dew point temperature data are calculated from the corresponding bias-corrected RCM-driven daily dew point temperature data, and the results are shown in Figure 9. The effects of climate change can be considered by modifying the $D_{1 d}$ in (7) according to the expected trend $D_{t}^{f}$.

\section{Future PMPs Estimation considering Climate Change}

5.1. Future Dew Point Temperatures Rising Trend Analysis. As a result of investing future 12-hour 100-year dew point 


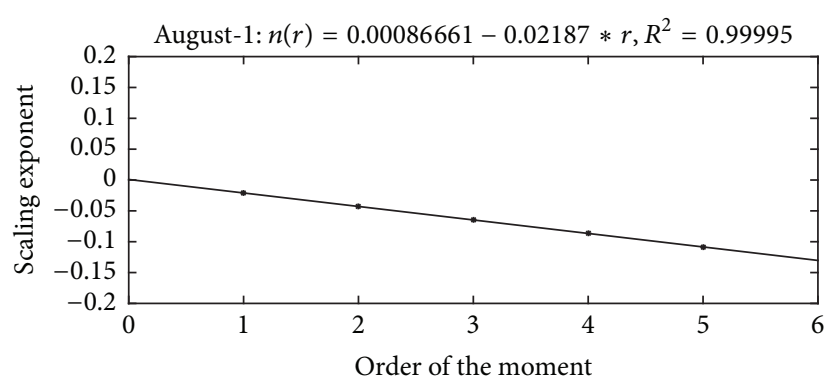

(a) Scaling of moments

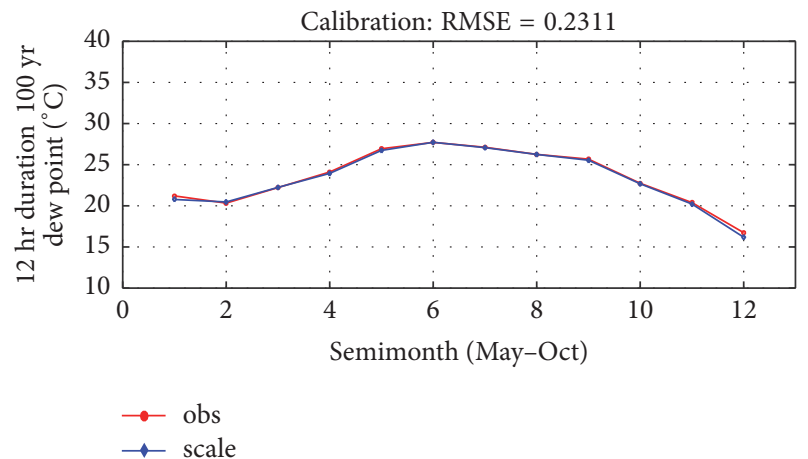

(b) Calibration

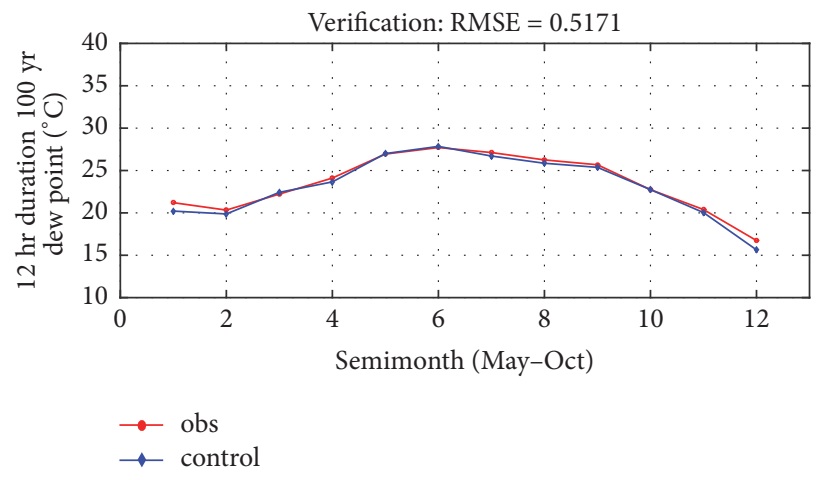

(c) Verification

FIGURE 6: Verification results of scale-invariance technique.

temperature for climate change scenarios, future 12-hour 100year dew point temperature has an upward trend, but the trend is not monotonic. In order to confirm when the future year reaching the highest dew point temperature is in each RCP scenario, the 12-hour 100-year dew point temperature projection data in July and August when most rainfall occurs are analyzed (Figure 10). Figure 10(a) shows the result of demonstrating when is the critical year in future extreme dew point temperature series derived under RCP 2.6. In the case of Station 1 (Sokcho site), the data reaches the maximum value in 2083, and after 2083, the data is decreased. The dotted line represents the average of years reaching the maximum value for each site. While the maximum value appears in about 2080 in the case of RCP 2.6 scenario, the extreme dew point temperature reaches the maximum value in about 2090 in the case of RCP 4.5 scenario. One can find that RCP 8.5 scenario shows the maximum value in 2100 .

In addition, the trend of the extreme dew point temperature series is analyzed for each site and for climate change scenarios. Figure 8 shows the trend in various sites, and one can see that the trends are very similar. While the rising rate is increased by RCP 2.6, RCP 4.5, and RCP 8.5 order, the increasing pattern of RCP 6.0 differs from other RCPs.

Reflecting this result, the base years for estimating PMPs according to future climate change scenarios were determined to be 2040, 2080, and 2100. After resetting the moisture maximization ratios and various storm transposition ratios based on future 12-hour 100-year dew point temperature series, PMPs at the base years under climate change scenarios are estimated.

\subsection{Future PMPs Estimation}

5.2.1. Comparison of the Estimation Results according to Climate Change Scenarios. In this section, future PMPs are estimated in the base years by using the dew point temperature projection based on RCP climate change scenarios, and the rate of change in future PMPs compared to current PMPs are investigated. Figure 12 shows the PMP change rate maps of duration 12-hour and effective area $25 \mathrm{~km}^{2}$ and duration 24hour and effective area $10,000 \mathrm{~km}^{2}$ at the base year 2100 . As can be seen in Figure 12, PMPs change rate is larger at coastal regions than inland regions for all RCPs. In addition, one can see that changes in PMPs are spatially very different.

Figure 13 shows the rate of change in future PMPs compared to current PMPs at the base years 2040, 2080, and 2100, respectively. For the base year 2040 under RCP 2.6, PMPs with more than 18-hour durations are generally expected to increase by about $10 \%$. Additionally, PMP with duration 24-hour and effective area $25 \mathrm{~km}^{2}$ is projected to increase by about $9 \%$, and this means that PMPs may have a tendency to increase year by year by $0.8 \mathrm{~mm}$. For the base year 2080 under RCP 2.6, PMPs with more than 18-hour 

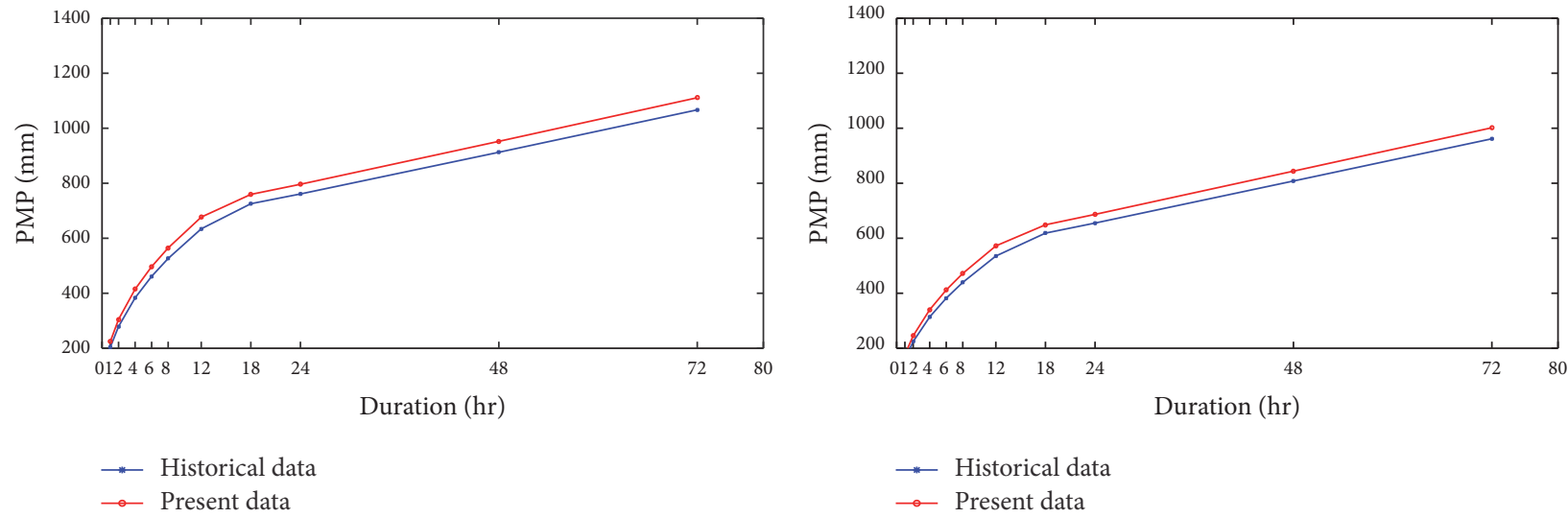

(a) $25 \mathrm{~km}^{2}$

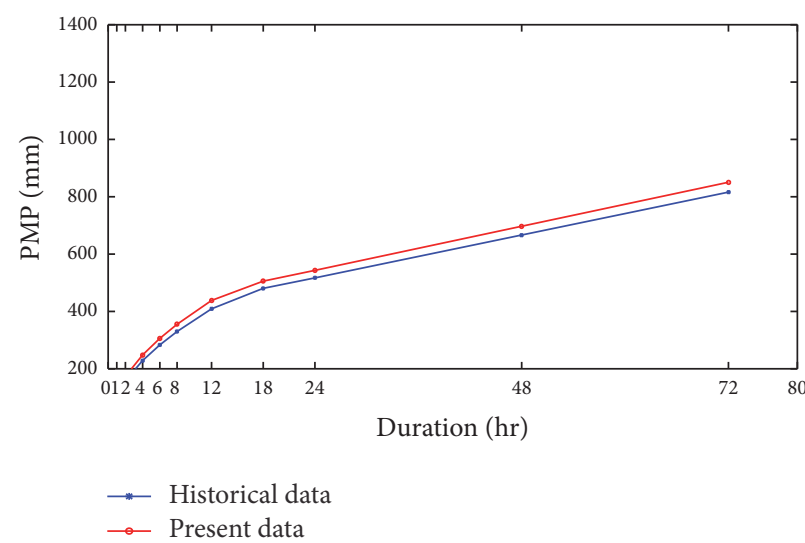

(c) $900 \mathrm{~km}^{2}$

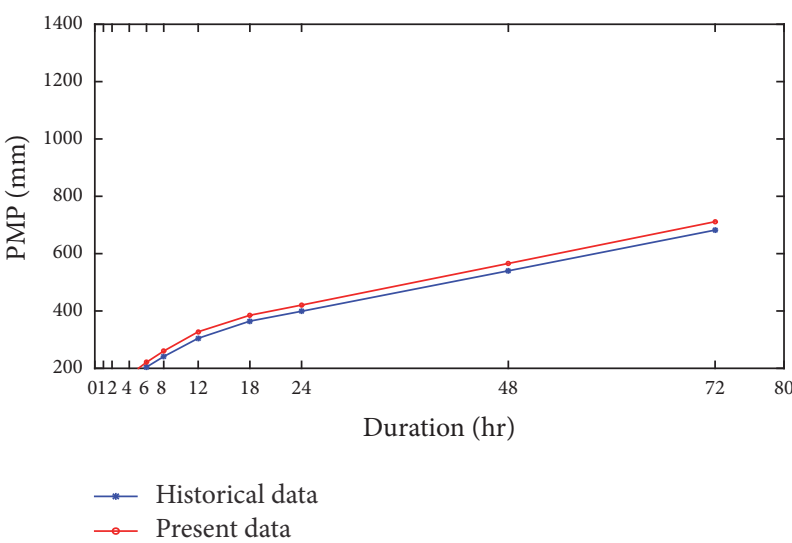

(d) $10,000 \mathrm{~km}^{2}$

FIGURE 7: Comparison between observed PMPs and present climate-simulated PMPs.

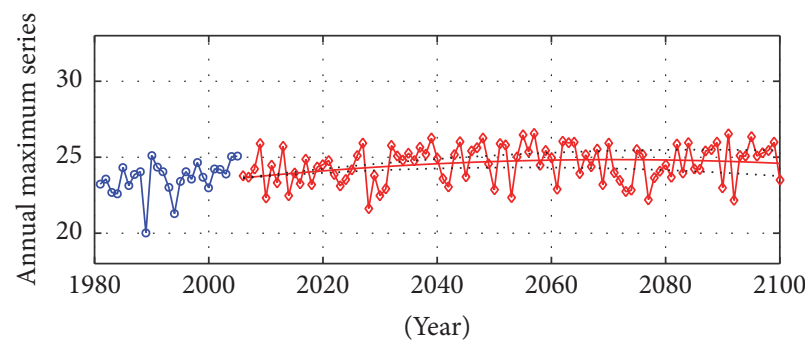

(a) RCP 2.6

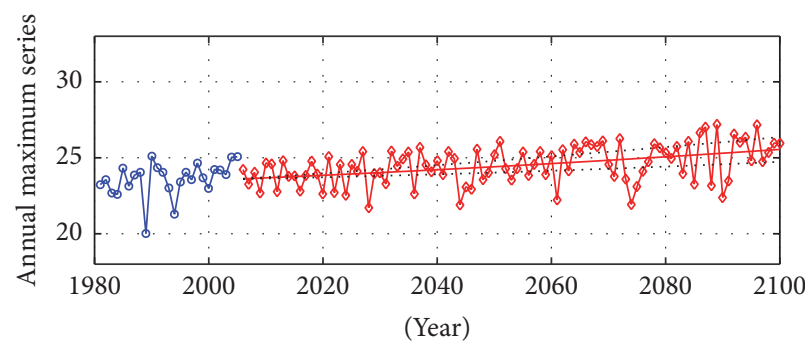

(c) RCP 6.0

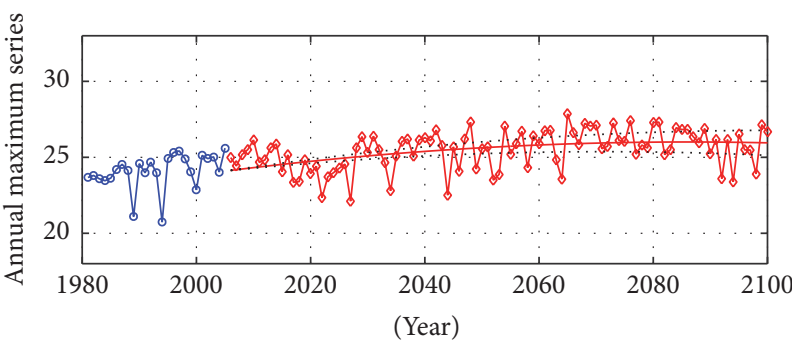

(b) RCP 4.5

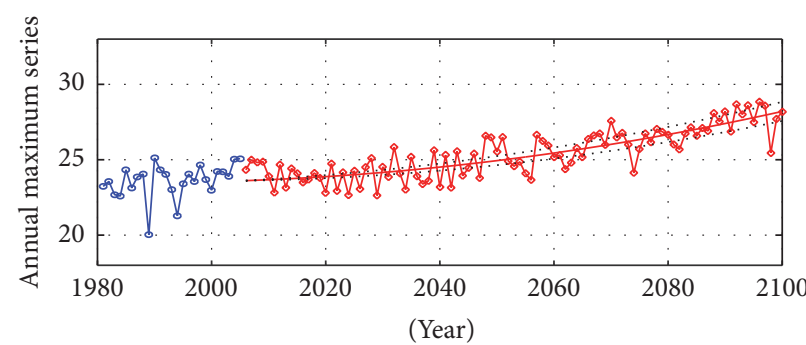

(d) RCP 8.5

FIGURE 8: Annual maximum daily dew point temperature projection and its uncertainty. 

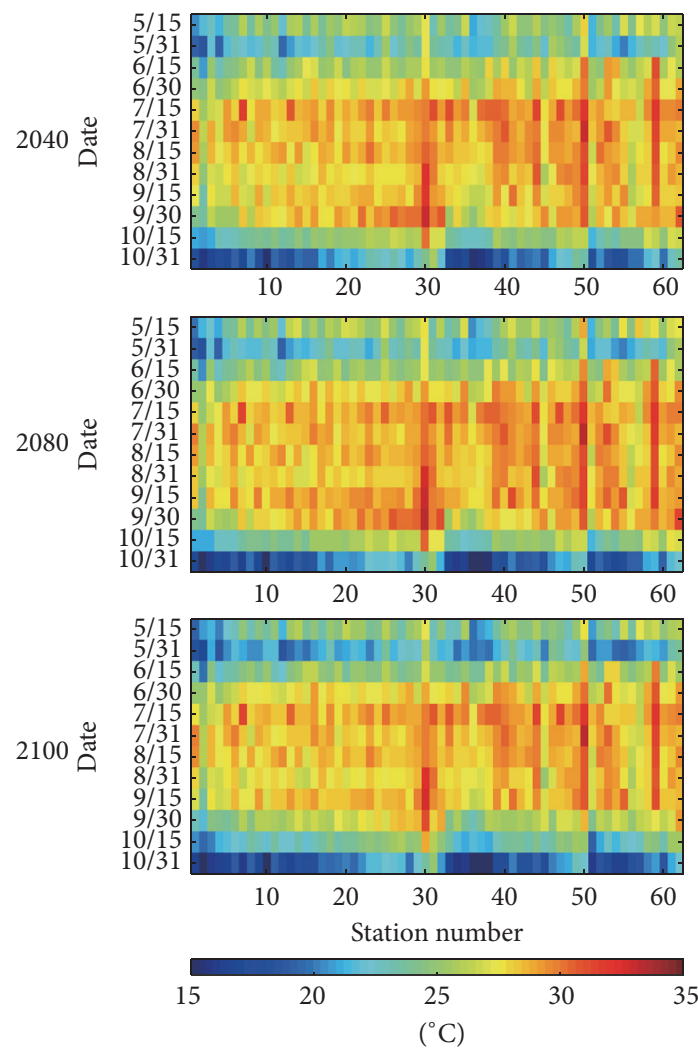

(a) RCP 2.6
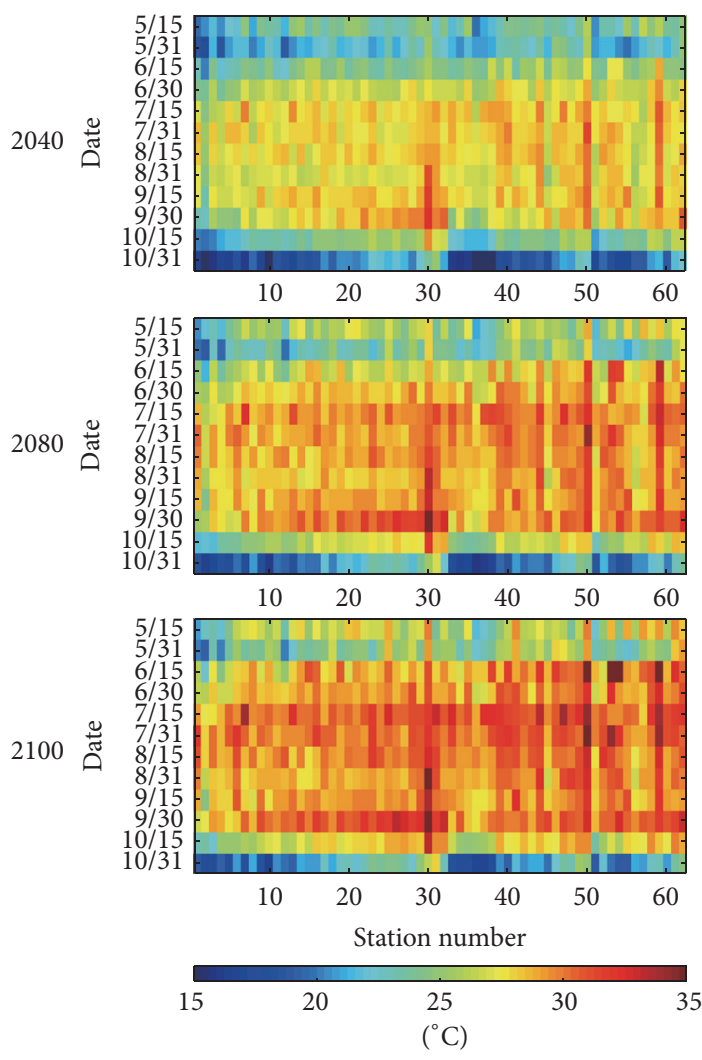

(c) RCP 6.0
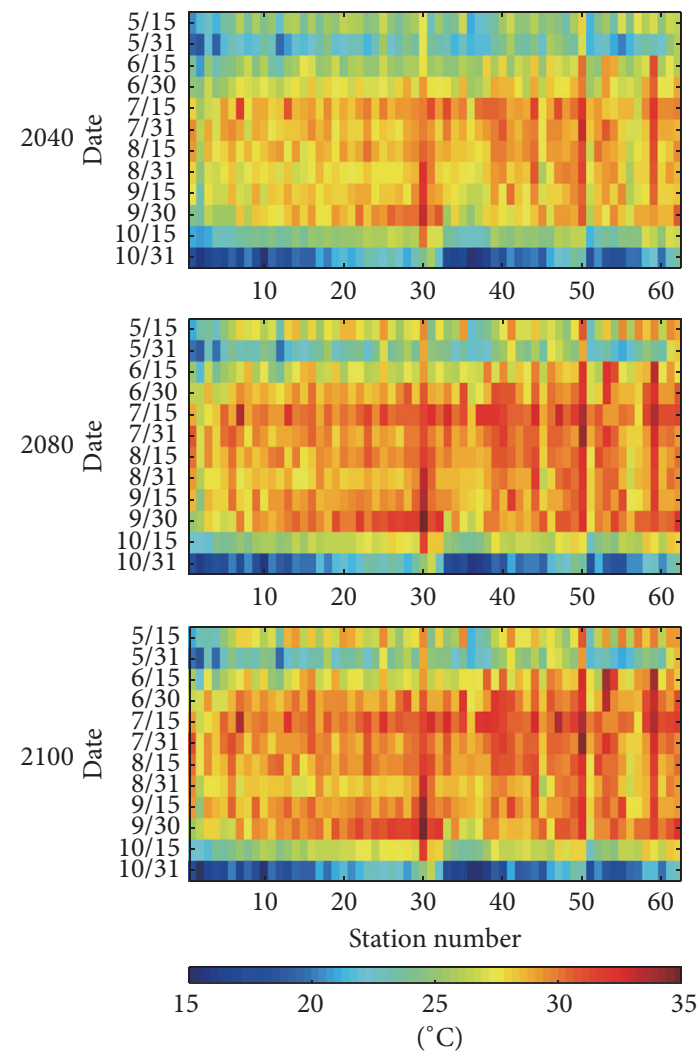

(b) RCP 4.5
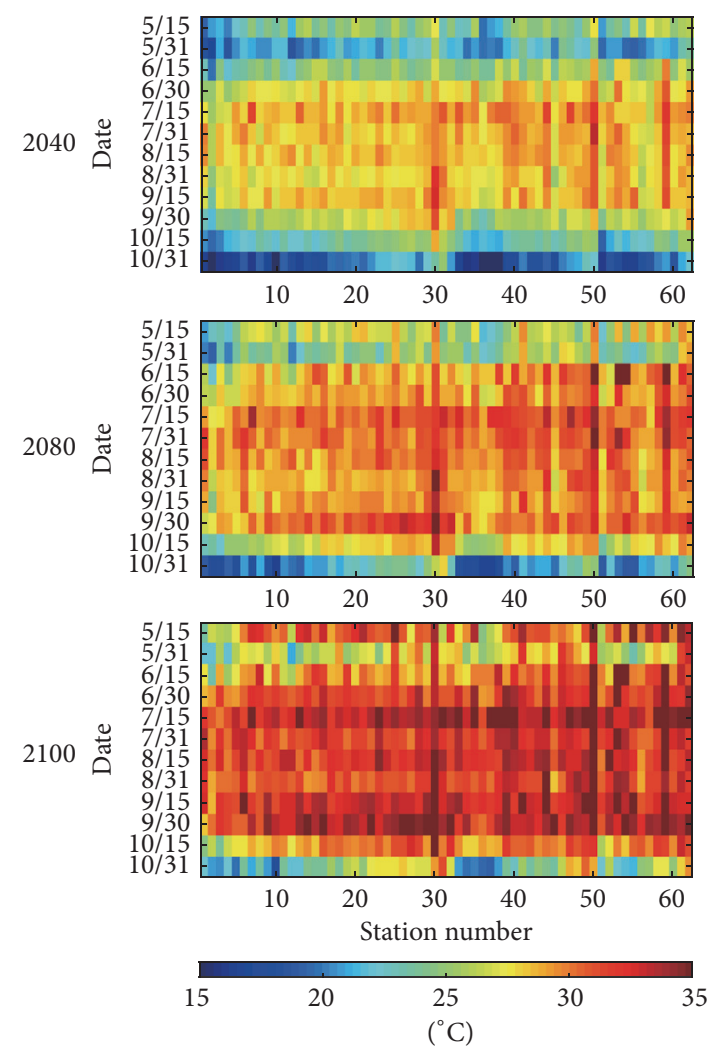

(d) RCP 8.5

Figure 9: Future 12-hour duration 100-year dew point temperature. 


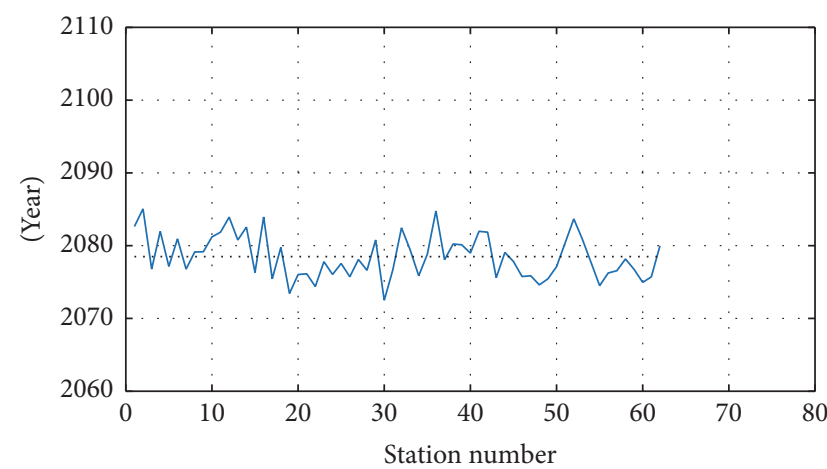

(a) RCP 2.6

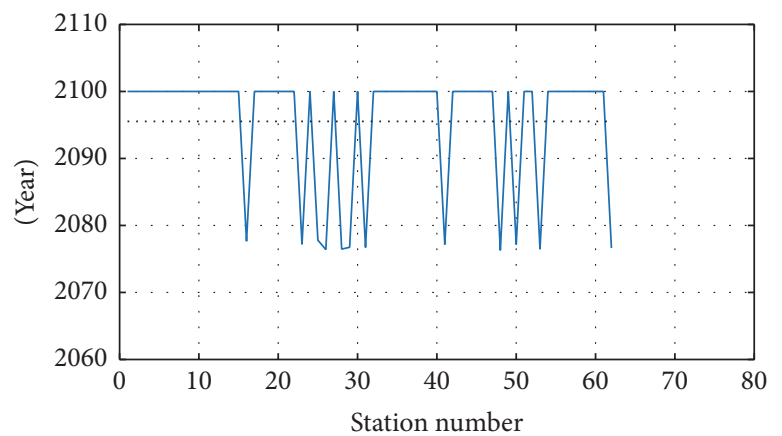

(c) RCP 6.0

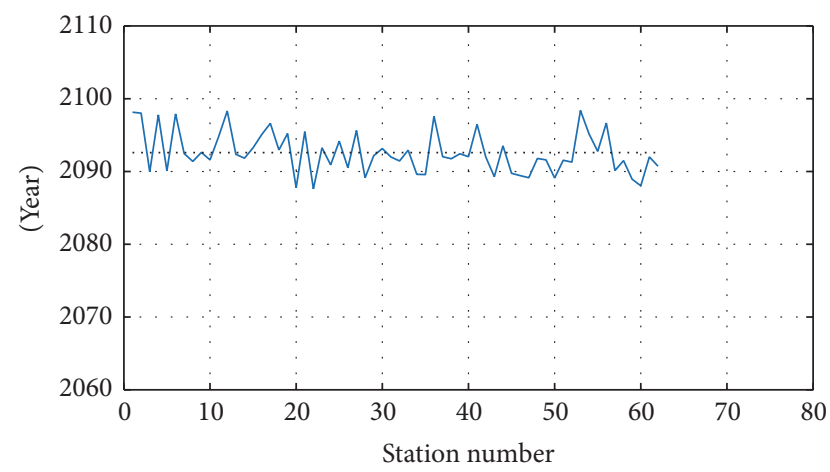

(b) RCP 4.5

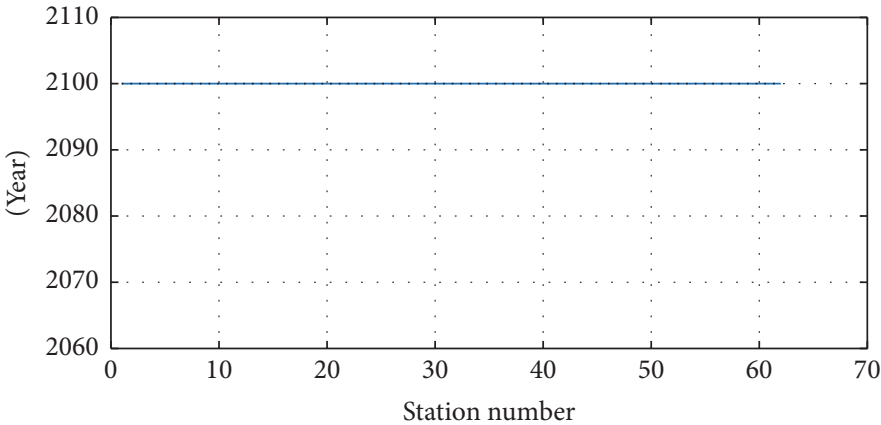

(d) $\mathrm{RCP} 8.5$

FIGURE 10: Identification of the year reaching the maximum 12-hour 100-year dew point temperature.

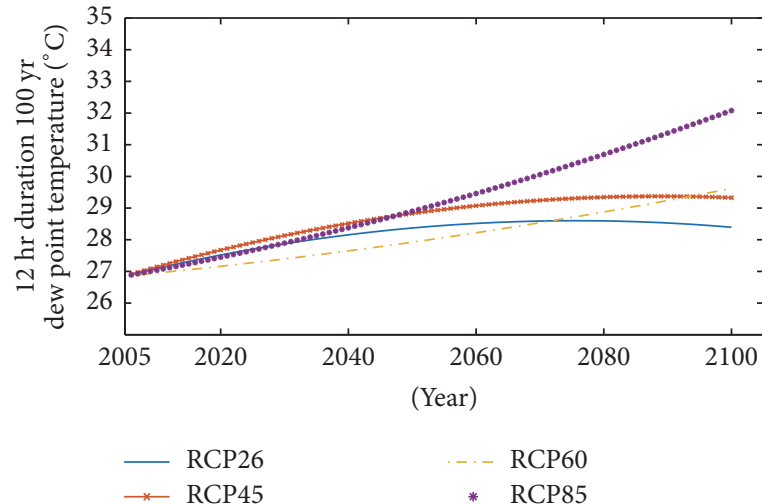

(a) Seoul

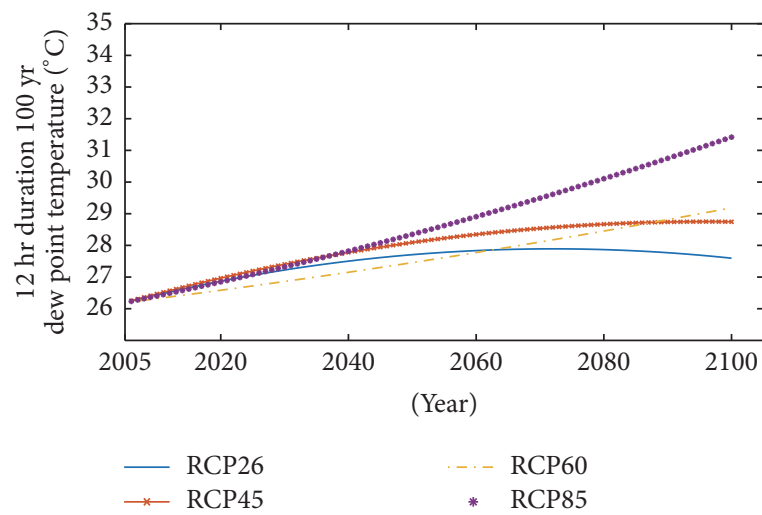

(c) Daegu

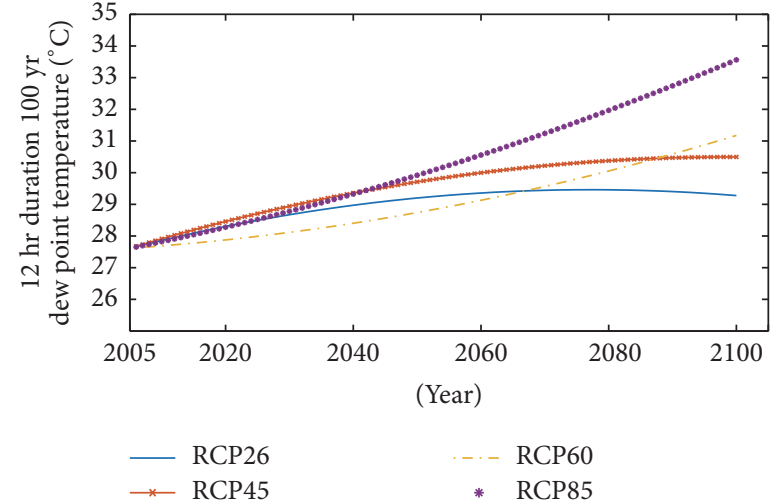

(b) Busan

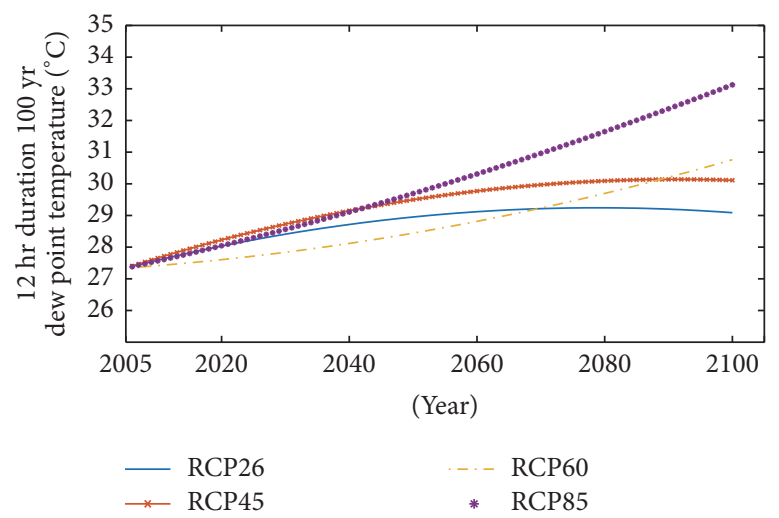

(d) Namhae

FIgURE 11: Trend of future extreme dew point temperature. 

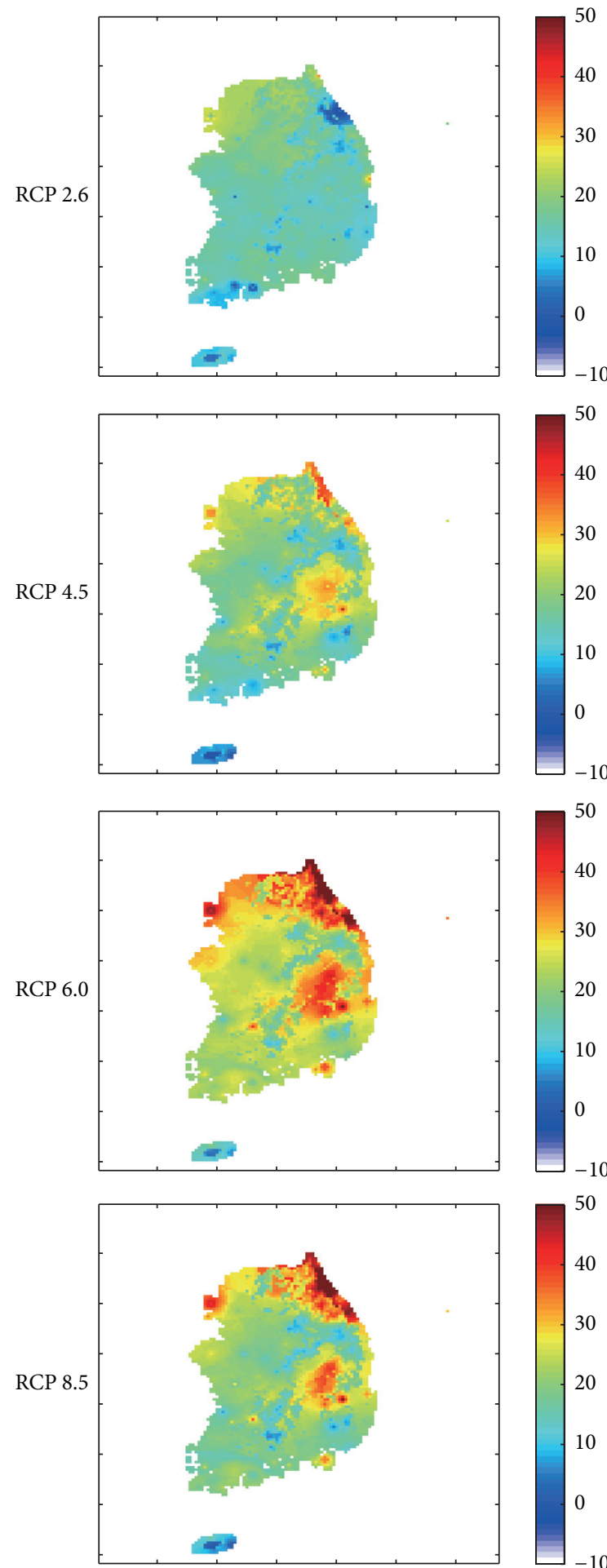

(a) $12 \mathrm{hr}-25 \mathrm{~km}^{2}$

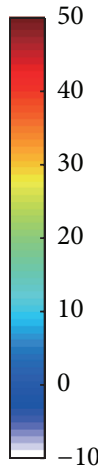

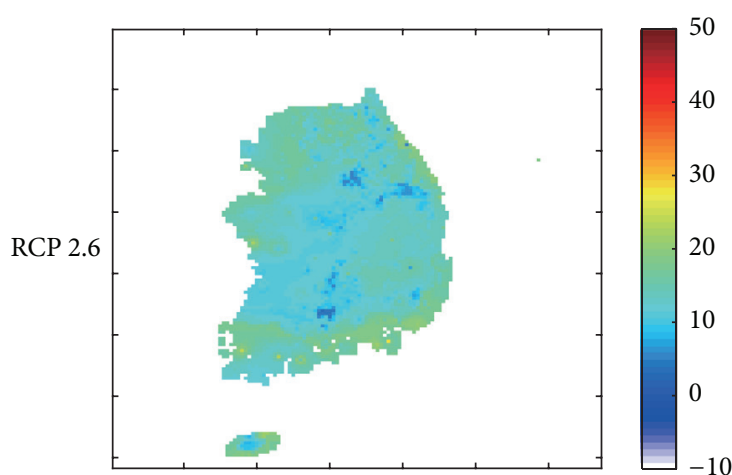
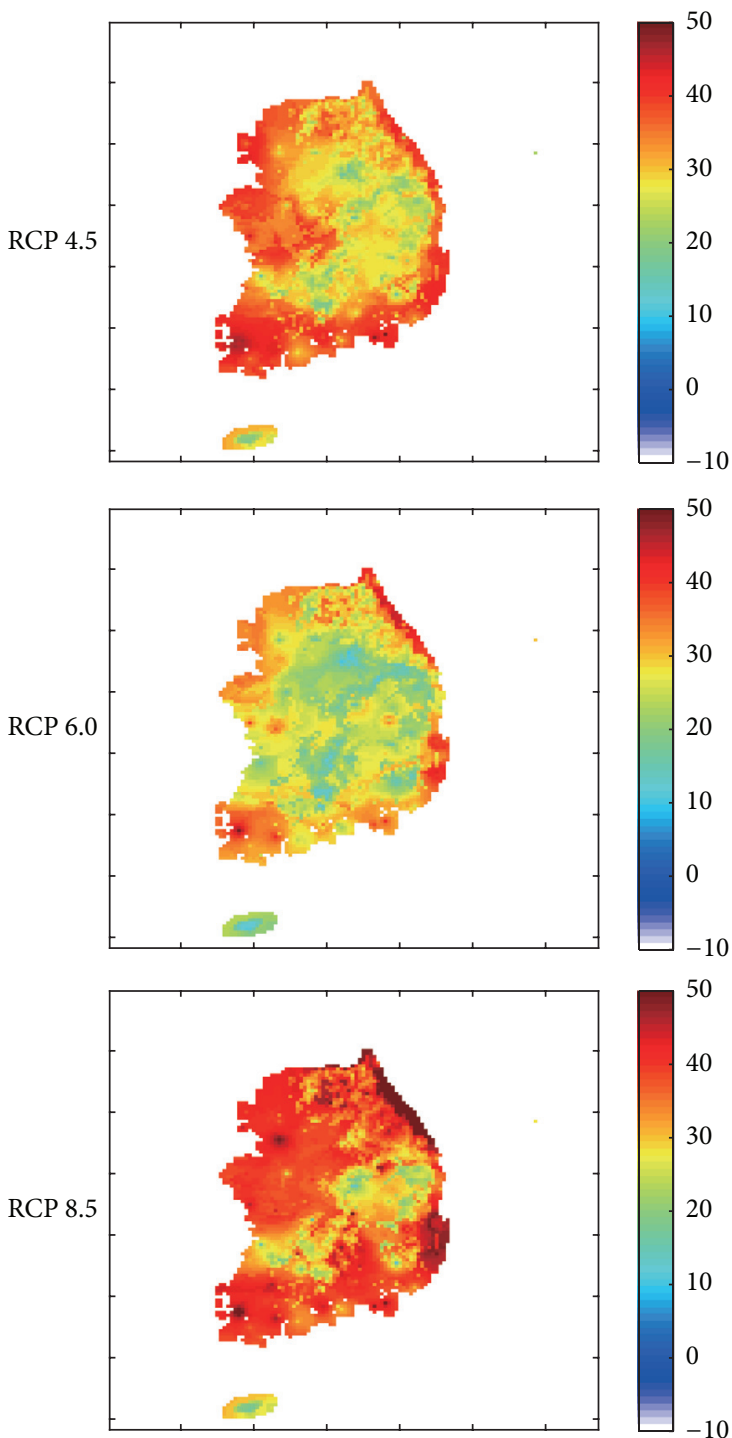

(b) $24 \mathrm{hr}-10,000 \mathrm{~km}^{2}$

FIGURE 12: Change rate (\%) of PMPs at the base year 2100.

durations are generally expected to increase by about $12 \%$, but after 2080, PMPs are found to be decreased. The reason of this increase-decrease pattern is that future 12-hour 100year dew point temperature series under RCP 2.6 have their maximum value at about 2080 (see Figure 11). However, PMPs with relatively shorter durations are found to be increased persistently until 2100.

For RCP 4.5, PMPs with more than 18-hour durations are mostly expected to increase by about $12 \%$ at the base year 2040. In general, PMPs under RCP 4.5 are projected to be 


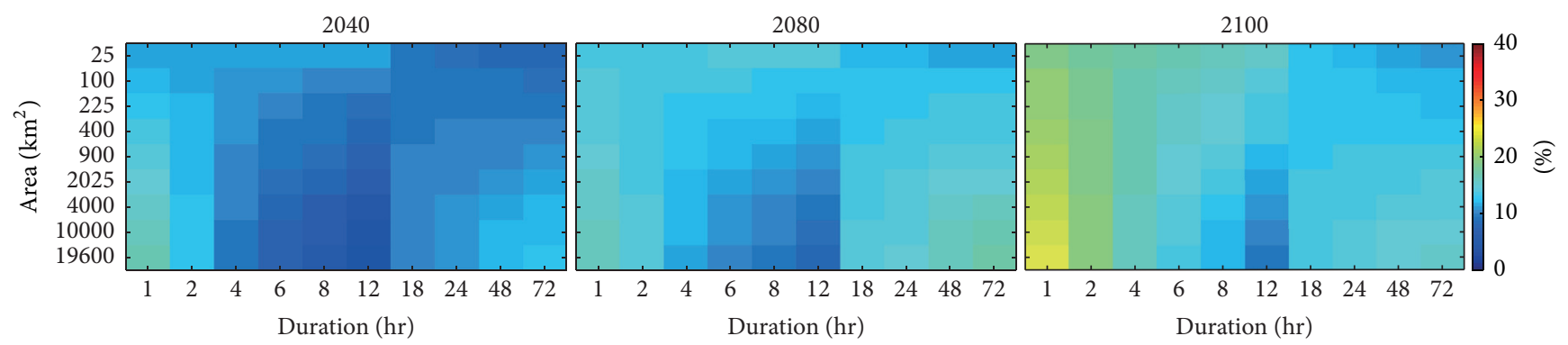

(a) RCP 2.6
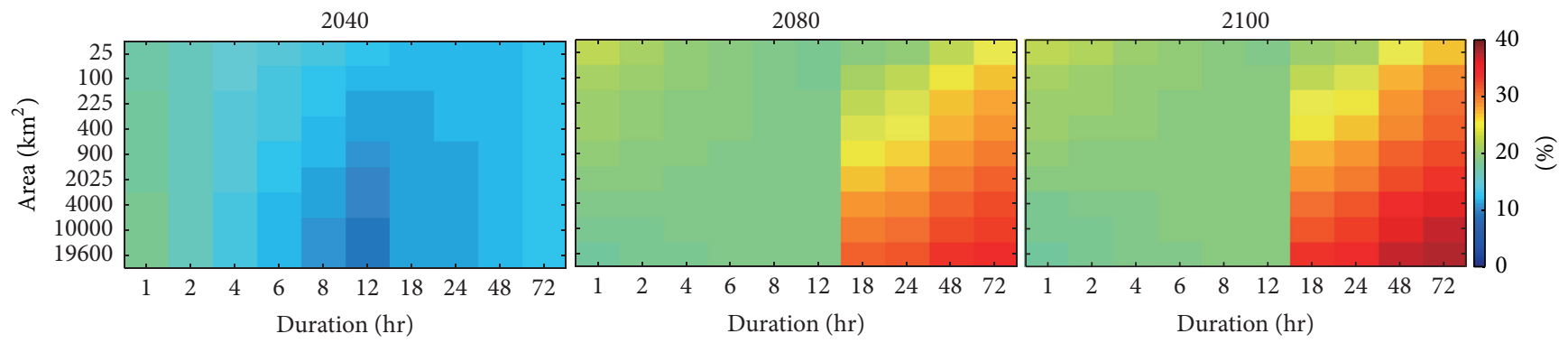

(b) RCP 4.5
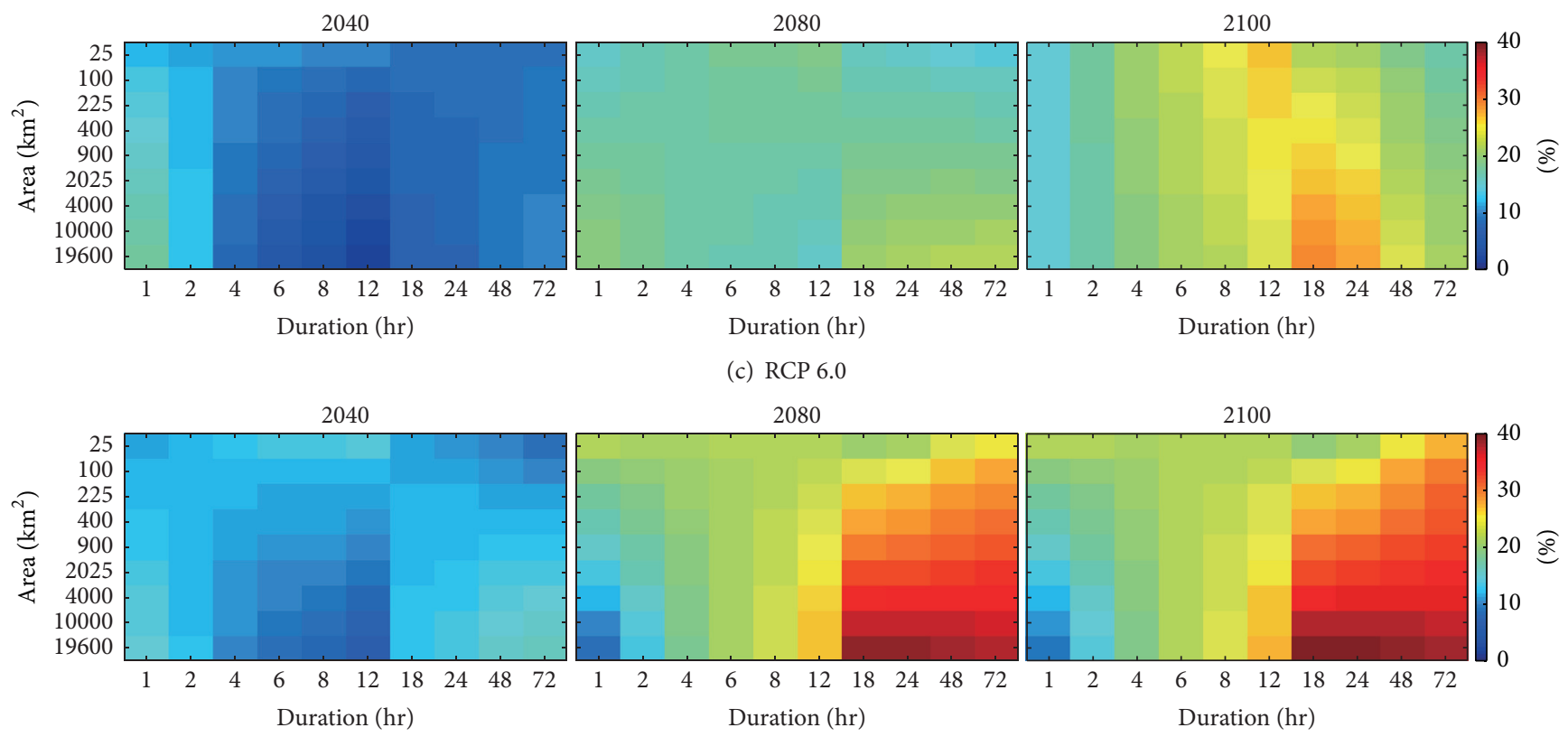

(d) $\mathrm{RCP} 8.5$

FIGURE 13: PMPs change rate for RCPs and the base years.

larger that RCP 2.6, and PMPs at the base year 2080 and 2100 are found to have similar values. PMPs may have a tendency to increase year by year by about $2 \mathrm{~mm}$ until 2080, and after that, PMPs do not increase any more.

For RCP 6.0, PMPs do not increase evenly with respect to durations and effective areas but generally are found to be persistently increased until 2100. PMPs at the base year 2100 are projected to increase by about $22 \%$.

For RCP 8.5, the most extreme increases of PMPs are predicted. While PMPs for RCP 8.5 show a similar growth rate for other RCPs until 2040, after that, the growth rate is projected to grow significantly. In particular, this growth behavior becomes more evident with relatively longer durations and larger effective areas. PMPs with more than 18hour durations are found to increase by about 30\% at the base year 2010 compared to current PMPs, and this result is consistent with Kunkel et al. [6] who reported the change of future precipitable water in East Asia region.

Figure 13 shows the result examining the PMP change with respect to the base years and climate change scenarios in terms of duration and effective area. The difference of PMP change for RCPs is not large, but after 2080, the difference for 


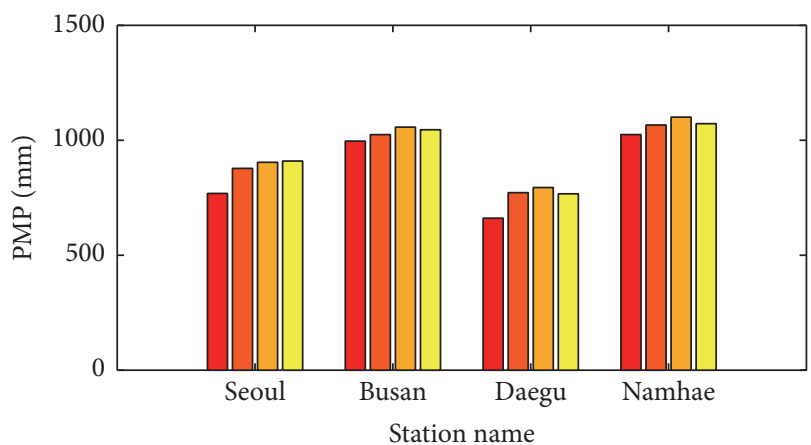

Present 2040

(a) RCP 2.6

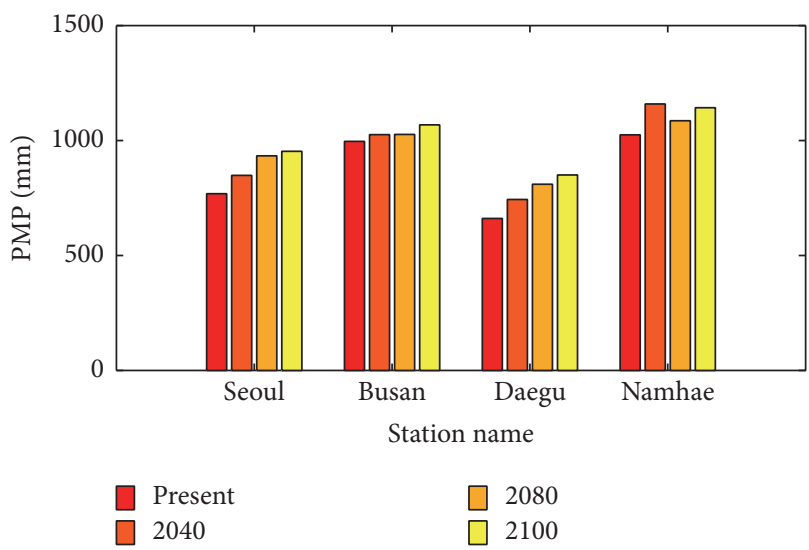

(c) RCP 6.0
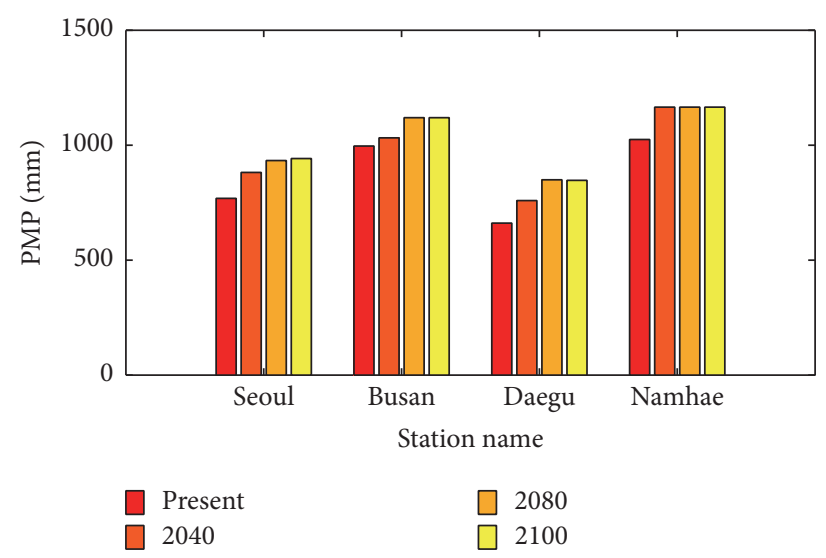

(b) RCP 4.5

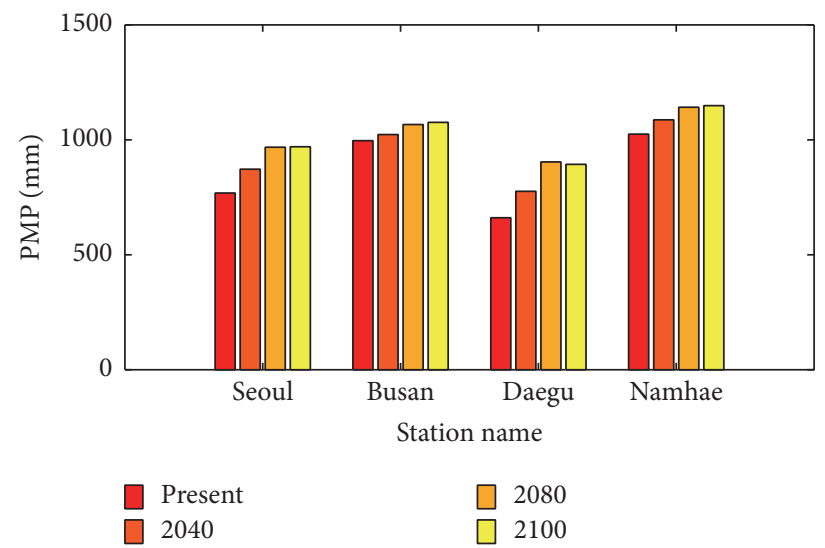

(d) RCP 8.5

FIGURE 14: Temporal behavior of PMP projection at each site and each RCP.

future climate change scenarios becomes clearer. In addition, for RCP 4.5 and 8.5, PMPs with longer durations and larger effective area are increased relatively larger. For RCP 6.0, the difference of PMP change for durations and effective areas is relatively small.

5.2.2. Comparison of Various Regional PMP Trends. In this section, using PMPs estimated with duration 24-hour and effective area $25 \mathrm{~km}^{2}$, the change pattern in PMPs is investigated with focus on sites and RCP scenarios.

Figure 14 shows the temporal behavior of PMP projection results with respect to sites and RCPs. Figures 14(a) and 14(b) can be drawn from RCP 2.6 and 4.5, respectively, and PMPs reach the maximum value in all 4 sites (Seoul, Busan, Daegu, and Namhae) at the base year 2080. After 2080, PMPs do not increase any more. Figures 14(c) and 14(d) is the result obtained from RCP 6.0 and 8.5, respectively, and persistently increasing trends are found in these sites, with the exception of Daegu for RCP 8.5.

Figure 15 shows the difference of PMP projection results according to future climate change scenarios. For 3 sites (Seoul, Busan, and Daegu) in 2040, it is found that there is only a little difference in PMP projections obtained from all 4 RCPs. However, in the case of Namhae, PMPs under RCP 4.5 and 6.0 are larger. In 2080 and 2100, PMPs have the maximum value under RCP 4.5 or 8.5 at all 4 sites. However, one can find that differences between RCPs appear differently by inland regions (Seoul and Daegu) and coastal regions (Busan and Namhae). One should keep in mind that extreme events have greater spatial variability compared to mean values.

\section{Conclusion}

The estimation of probable maximum precipitations taking into account climate change impact is needed. Regional climate models such as the HadGEM3-RA are used as a tool to meet this requirement. In this study, future PMPs in Korea were investigated under climate change scenarios driven from the regional climate model developed by Korea Meteorological Administration with major focus on future dew point temperature projection. To investigate the variation of PMPs considering the impact of climate change, two procedures were performed:

(1) Reproduction of future climate information to estimate PMPs from RCM-driven outputs.

(2) Future PMPs estimation and analysis of estimation results. 


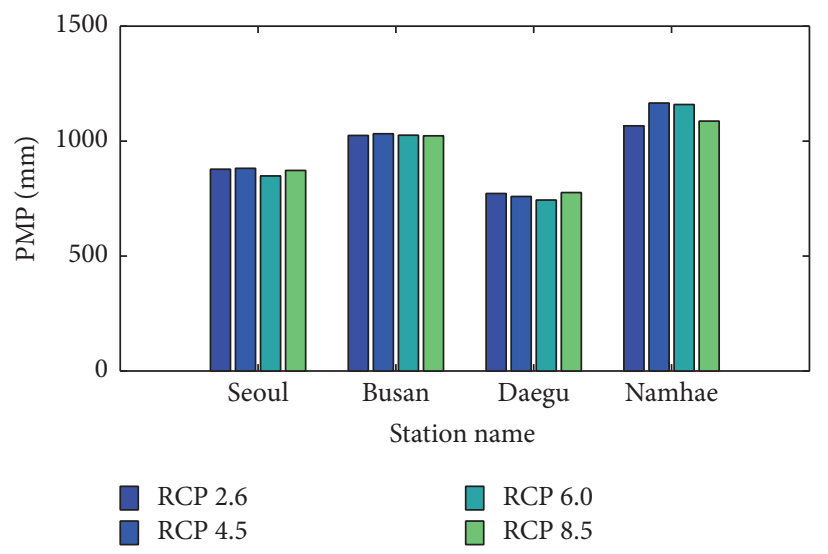

(a) 2040

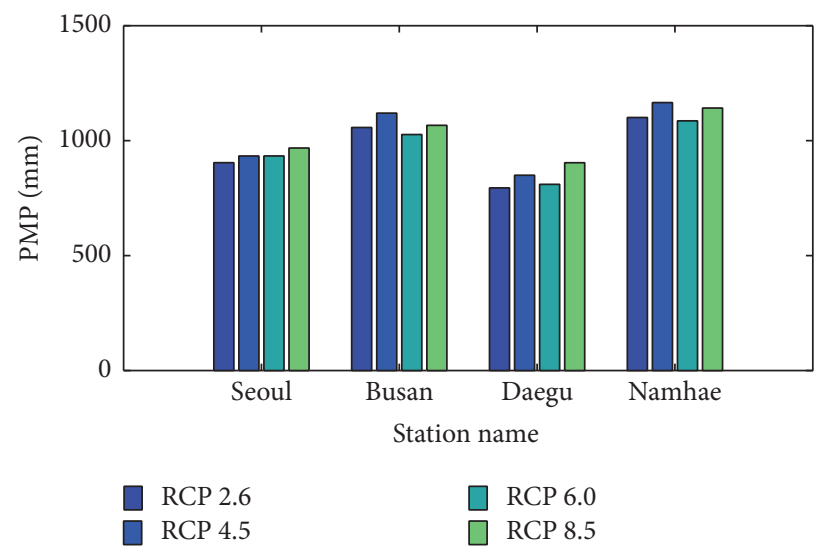

(b) 2080

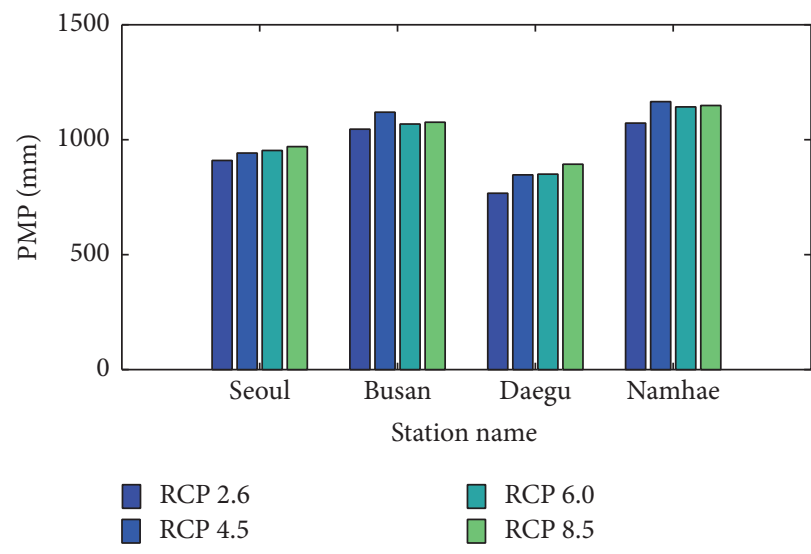

(c) 2100

FIGURE 15: Difference driven by RCPs in PMP projection.

After performing the bias correction procedure of future daily dew point temperature data driven by RCM, future 12-hour duration 100-year dew point temperature data was calculated from the corresponding daily data using the scale-invariance techniques.

Although the results appear different for each RCP scenario, it can be confirmed that PMPs have a generally increasing trend for all RCPs. Particularly, for RCP 8.5 which represents the most extreme, it can be found that PMPs are expected to be increased about $30 \%$ as compared to the present. This is consistent with Kunkel et al. [6] who reported that the increments in maximum precipitable water for the Korean Peninsula are approximately $20 \%-30 \%$ by $2071-2100$.

However, the result will be different depending on climate models applied and a comprehensive climate change impact must be accounted in this fact. Further studies will be needed later for this issue.

In this study, the bias correction procedure and scaleinvariance technique were carried out. This procedure provides a consistent approach to account for climate change impact in the maximization of precipitable water. On average, the results for Korea show a mean increase of the PMP of about $15-30 \%$, when comparing 1981-2005 versus 20812100. These results are quite representative for the territory of the Republic of Korea. Indeed, a clear increase of PMPs is reported, although with a high spatial variability. The results show an overall significant increase of future PMPs throughout the current century compared to the recent past.

\section{Competing Interests}

The authors declare that they have no competing interests.

\section{Acknowledgments}

This research was supported by a grant (14AWMP-B08256401) from Advanced Water Management Research Program funded by Ministry of Land, Infrastructure and Transport of Korean government.

\section{References}

[1] World Meteorological Organization, Manual for Estimation of Probable Maximum Precipitation, Operational Hydrology Report no. 1, WMO no. 332, 2nd edition, 1986.

[2] J. L. Paulhus and C. S. Gilman, "Evaluation of probable maximum precipitation," Transactions American Geophysical Union, vol. 34, no. 5, pp. 701-708, 1953. 
[3] V. A. Myers, "The estimation of extreme precipitation as the basis for design floods-resume of practice in the United States," in Proceedings of the Leningrad Symposium on Floods and their Computation, vol. 1, pp. 84-101, International Association of Scientific Hydr ology, August 1967.

[4] F. P. Ho and J. T. Riedel, Seasonal Variation of 10-Square-Mile Probable Maximum Precipitation Estimates) United States East of the 105th Meridian, HMR 53, National Weather Service, National Oceanic and Atmospheric Administration, United States Department of Commerce, Washington, DC, USA, 1980.

[5] M. C. Casas, R. Rodríguez, M. Prohom, A. Gázquez, and A. Redaño, "Estimation of the probable maximum precipitation in Barcelona (Spain)," International Journal of Climatology, vol. 31, no. 9, pp. 1322-1327, 2011.

[6] K. E. Kunkel, T. R. Karl, D. R. Easterling et al., "Probable maximum precipitation (PMP) and climate change," Geophysical Research Letters, vol. 40, no. 7, pp. 1402-1408, 2013.

[7] S. A. Stratz and F. Hossain, "Probable maximum precipitation in a changing climate: implications for dam design," Journal of Hydrologic Engineering, vol. 19, no. 12, Article ID 06014006, 2014.

[8] M. A. Lagos-Zúñiga and X. Vargas M, "PMP and PMF estimations in sparsely-gauged Andean basins and climate change projections," Hydrological Sciences Journal, vol. 59, no. 11, pp. 2027-2042, 2014.

[9] A. N. Rousseau, I. M. Klein, D. Freudiger, P. Gagnon, A. Frigon, and C. Ratté-Fortin, "Development of a methodology to evaluate probable maximum precipitation (PMP) under changing climate conditions: application to southern Quebec, Canada," Journal of Hydrology, vol. 519, pp. 3094-3109, 2014.

[10] O. Lee, M. W. Park, J. H. Lee, and S. Kim, "Future PMPs projection according to precipitation variation under RCP 8.5 climate change scenario," Journal of Korea Water Resources Association, vol. 49, no. 2, pp. 107-119, 2016.

[11] IPCC, "Climate change 2014: synthesis report. Contribution of working groups I, II and III to the fifth assessment report of the intergovernmental panel on climate change," in Core Writing Team, R. K. Pachauri and L. A. Meyer, Eds., p. 151, IPCC, Geneva, Switzerland, 2014.

[12] World Meteorological Organization, "Manual on Estimation of Probable Maximum Precipitation(PMP)," WMO No. 1045, 2009.

[13] J. F. Miller, E. M. Hansen, and D. D. Fenn, "Probable maximum precipitation for the upper Deerfield River Drainage, Massachusetts/Nermont," NOAA Technical Memorandum NWS HYDRO 39, National Weather Service, U.S. Department of Commerce, Silver Spring, Md, USA, 1984.

[14] J. F. Miller, E. M. Hansen, D. D. Fenn, L. C. Schreiner, and D. T. Jensen, "Probable maximum precipitation estimates-United States between the continental divide and the 103rd meridian," HMR 55, National Weather Service, National Oceanic and Atmospheric Administration, United States Department of Commerce, Washington, DC, USA, 1984.

[15] E. Tomlinson, B. Kappel, G. Muhlestein, D. Hulstrand, and T. Parzybok, Statewide Probable Maximum Precipitation Study for Arizona, Applied Weather Associates, Monument, Colo, USA, 2013.

[16] B. Kappel, G. Muhlestein, D. Hultstrand et al., Probable Maximum Precipitation Study for Wyoming, Applied Weather Associates, Monument, Colo, USA, 2014.
[17] B. Kappel, E. Tomlinson, J. Haapala, and B. Sadden, "SusitnaWatana hydroelectric project probable maximum precipitation study," Tech. Rep. 14-07-REP, Alaska Energy Authority, 2014.

[18] U. Ehret, E. Zehe, V. Wulfmeyer, K. Warrach-Sagi, and J. Liebert, "HESS opinions 'should we apply bias correction to global and regional climate model data?"' Hydrology and Earth System Sciences, vol. 16, no. 9, pp. 3391-3404, 2012.

[19] E. Kim, H. I. Choi, M. J. Park, S. J. Cho, and S. Kim, "The effect of climate change on Korean drought occurrences using a stochastic soil water balance model," Scientific Research and Essays, vol. 6, no. 13, pp. 2771-2783, 2011.

[20] S. Hwang, Y. G. Her, and S. Chang, "Uncertainty in regional climate change impact assessment using bias-correction technique for future climate scenarios," Journal of The Korean Society of Agricultural Engineers, vol. 55, no. 4, pp. 95-106, 2013.

[21] P. Burlando and R. Rosso, "Scaling and multiscaling models of depth-duration-frequency curves for storm precipitation," Journal of Hydrology, vol. 187, no. 1-2, pp. 45-64, 1996.

[22] R. Rodríguez, X. Navarro, M. C. Casas et al., "Influence of climate change on IDF curves for the metropolitan area of Barcelona (Spain)," International Journal of Climatology, vol. 34, no. 3, pp. 643-654, 2014. 

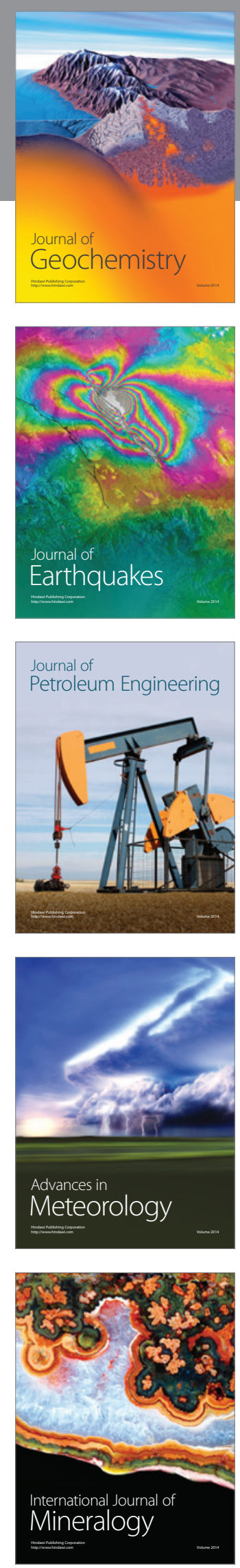
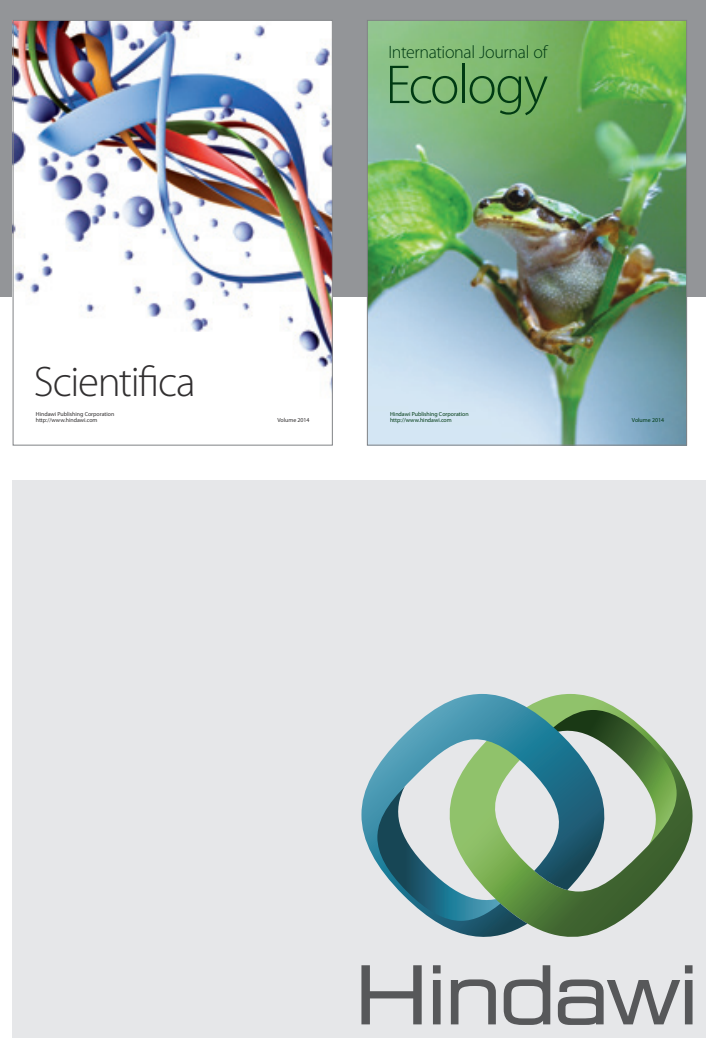

Submit your manuscripts at

http://www.hindawi.com
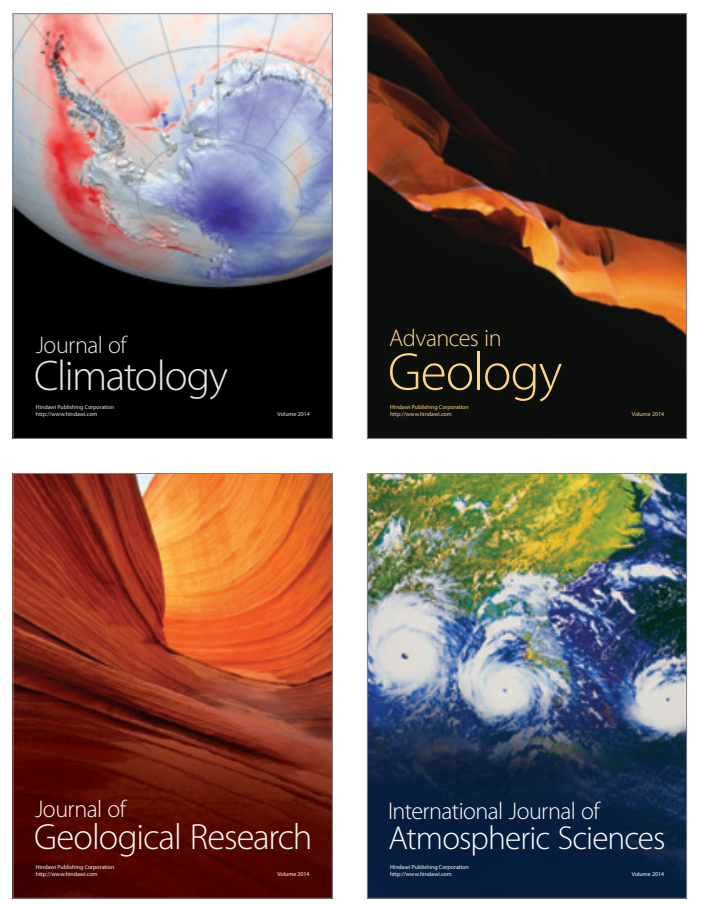

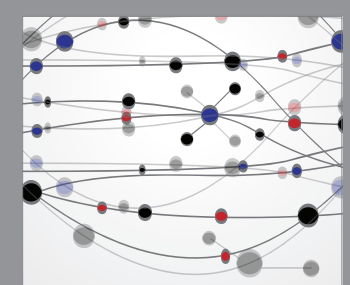

The Scientific

\section{World Journal}
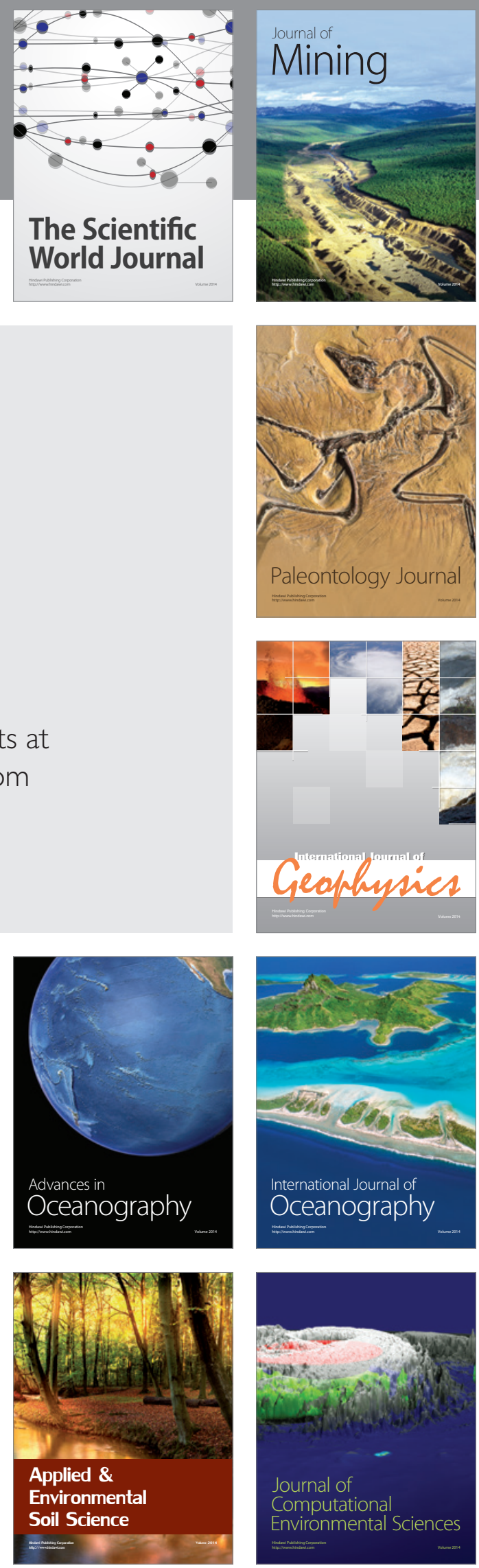